\title{
The Role of Stochastic Forcing in Generating ENSO Diversity ${ }^{\mathscr{O}}$
}

\author{
ERIN E. THOMAS AND DANIEL J. VIMONT \\ Department of Atmospheric and Oceanic Sciences, and Nelson Institute Center for Climatic Research, University of \\ Wisconsin-Madison, Madison, Wisconsin \\ MATTHEW NEWMAN \\ CIRES, University of Colorado Boulder, and NOAA/Earth System Research Laboratory/Physical Sciences Division, \\ Boulder, Colorado \\ CÉCILE PENLAND \\ NOAA/Earth System Research Laboratory/Physical Sciences Division, Boulder, Colorado \\ CRISTIAN MARTÍNEZ-VILLALOBOS \\ Department of Atmospheric and Oceanic Sciences, University of California, Los Angeles, Los Angeles, California
}

(Manuscript received 28 August 2017, in final form 28 August 2018)

\begin{abstract}
Numerous oceanic and atmospheric phenomena influence El Niño-Southern Oscillation (ENSO) variability, complicating both prediction and analysis of the mechanisms responsible for generating ENSO diversity. Predictability of ENSO events depends on the characteristics of both the forecast initial conditions and the stochastic forcing that occurs subsequent to forecast initialization. Within a linear inverse model framework, stochastic forcing reduces ENSO predictability when it excites unpredictable growth or interference after the forecast is initialized, but also enhances ENSO predictability when it excites optimal initial conditions that maximize deterministic ENSO growth. Linear inverse modeling (LIM) allows for straightforward separation between predictable signal and unpredictable noise and so can diagnose its own skill. While previous LIM studies of ENSO focused on deterministic dynamics, here we explore how noise forcing influences ENSO diversity and predictability. This study identifies stochastic forcing details potentially contributing to the development of central Pacific (CP) or eastern Pacific (EP) ENSO characteristics. The technique is then used to diagnose the relative roles of initial conditions and noise forcing throughout the evolution of several ENSO events. LIM results show varying roles of noise forcing for any given event, highlighting its utility in separating deterministic from noise-forced contributions to the evolution of individual ENSO events. For example, the strong 1982 event was considerably more influenced by noise forcing late in its evolution than the strong 1997 event, which was more predictable with long lead times due to its deterministic growth. Furthermore, the 2014 deterministic trajectory suggests that a strong event in 2014 was unlikely.
\end{abstract}

\section{Introduction}

El Niño-Southern Oscillation (ENSO) is the dominant source of interannual climate variability on Earth (see, e.g., Wallace et al. 1998), with large impacts on global

Supplemental information related to this paper is available at the Journals Online website: https://doi.org/10.1175/ JCLI-D-17-0582.s1.

Corresponding author: Erin Thomas, eethomas3@wisc.edu climate patterns (Diaz et al. 2001; Alexander et al. 2002). While theories exist to explain the gross spatial and temporal characteristics of ENSO event evolution (Zebiak and Cane 1987; Battisti 1988; Suarez and Schopf 1988; Battisti and Hirst 1989; Penland and Sardeshmukh 1995; Jin 1997; Neelin et al. 1998), individual ENSO events show considerable diversity in their spatial details, evolution, predictability, and timing [see Capotondi et al. (2015) for a review]. Spatial diversity, often characterized using terms such as central Pacific (CP) or eastern Pacific (EP) (e.g., Ashok et al. 2007; Kao and Yu 2009; Kug et al. 2009, 2010a; 
Yu and Kim 2011; Newman et al. 2011b; Kim et al. 2012a; Kim et al. 2012b; Capotondi 2013; Capotondi et al. 2015), arises due to the varying roles of different physical processes allowing any given ENSO event to have a continuous range of CP and EP characteristics (Karnauskas 2013; Capotondi et al. 2015). This study provides a general framework to identify and characterize the role of these physical processes in generating ENSO diversity within the context of the dynamically evolving ENSO system.

Several studies have shown that atmospheric and oceanic midlatitude variability help generate initial structures in the tropical Pacific that lead to ENSO diversity. Vimont et al. (2014) use linear inverse modeling (LIM; Penland and Sardeshmukh 1995) to identify optimal initial conditions leading to ENSO events with either CP or EP characteristics. They find that CP-related initial conditions are associated with the Pacific meridional mode (PMM; Chiang and Vimont 2004) through the "seasonal footprinting mechanism" (Vimont et al. 2001, 2003a, 2003b, 2009; Zhang et al. 2009; Yu and Kim 2011; Park et al. 2013). Southern Hemisphere atmospheric variability has also been shown to generate initial heat content anomalies that can influence EP-type ENSO events (You and Furtado 2017). Other studies show that ENSO diversity is associated with initial oceanic heat content anomalies, ocean dynamics, and basin-wide thermocline variations (Meinen and McPhaden 2000; Kao and $\mathrm{Yu}$ 2009; Kug et al. 2010a; Horii et al. 2012; Fedorov et al. 2015). Finally, ENSO initial conditions have been associated with forcing from the tropical Indian Ocean or from the subtropical Atlantic (e.g., Penland and Matrosova 2006, 2008; Rodríguez-Fonseca et al. 2009; Martín-Rey et al. 2012).

Variations in stochastic forcing (here we loosely define stochastic or external forcing as forcing that is external to the essential deterministic dynamics that produce ENSO variability) have also been shown to generate ENSO diversity. Newman et al. (2011b) show that ENSO diversity arises naturally in a stochastically forced linear inverse model simulation with an unchanging dynamical description, confirming that stochastic forcing is a sufficient condition for generating ENSO diversity. Studies also show that ENSO events with strong EP characteristics, such as the 1997/98 El Niño event, are influenced by westerly wind busts (WWBs) and zonal wind variability in the western tropical Pacific (Boulanger and Menkes 1999; McPhaden 1999; Harrison and Chiodi 2009; Kug et al. 2010b; Fedorov et al. 2015; Chen et al. 2015). It has also been shown that strong ENSO events, which typically have EP characteristics, are more strongly influenced by state-dependent wind stress variations (Perez et al. 2005; Gebbie et al. 2007; Kapur and Zhang 2012; Levine et al. 2016).
LIM provides an observationally based, empirical model that approximates slow dynamical processes via a deterministic linear dynamical operator, and the effect of fast processes as Gaussian white noise. Penland and Sardeshmukh (1995) use LIM to show that ENSO growth can occur via nonnormal processes in a linearly stable dynamical system. In that case, stochastic forcing both maintains climatological variance and explains the observed temporal irregularities of ENSO variability. Penland (1996) shows that a time-independent linear approximation of the slow dynamics of the Indo-Pacific forced by seasonally varying noise can account for observed temporal ENSO behaviors, such as the seasonal ENSO phase locking.

Demonstrated forecast skill of the LIM (e.g., Penland and Magorian 1993; Penland and Matrosova 1998; Newman 2007; Alexander et al. 2008; Newman et al. 2011a; Newman and Sardeshmukh 2017) motivated its use as a diagnostic tool for understanding the physical processes that generate ENSO variability. LIM allows for an objective, observationally grounded calculation of the initial state that maximizes deterministic growth toward a specified final state. Previous studies show that the optimal initial conditions maximizing tropical Pacific SST growth contain SST anomalies north of the equator and in the far eastern equatorial Pacific (Penland and Sardeshmukh 1995; Newman et al. 2011a). Newman et al. (2011a) also show that the optimal initial conditions contain positive thermocline depth anomalies throughout the central tropical Pacific. Capotondi and Sardeshmukh (2015) use LIM to show the importance of the thermocline initial state and suggest SST precursors alone are not sufficient to capture the development of ENSO diversity.

A variety of physical processes have been proposed to explain ENSO diversity. In this study, we take a forecast perspective in which the evolution of an individual ENSO event from a given time depends on (i) the specific set of initial conditions that determine how the system will evolve along its deterministic trajectory, as well as (ii) the "external" forcing that, when convolved with the dynamics, pushes the system away from (in general) the deterministic trajectory. A third possibility exists that ENSO diversity is caused by variations in the internal dynamics responsible for ENSO evolution (e.g., Fedorov and Philander 2000, 2001; An and Wang 2000; An and Jin 2000; Wang and An 2002; Yeh et al. 2009; Capotondi and Sardeshmukh 2017). Here, we focus solely on the role of the initial conditions and stochastic forcing in generating ENSO diversity.

Although previous studies have characterized the optimal initial conditions for maximum CP and EP growth (Vimont et al. 2014; Capotondi and Sardeshmukh 2015), 
the specific structures within the stochastic forcing that generate these initial conditions have not been identified. In this study, we characterize the role of stochastic forcing mechanisms in generating CP or EP characteristics using a LIM forecast framework to separate the deterministic evolution of the tropical Pacific from the unpredictable, or noise forced, evolution. Within the forecasting framework, it is possible the noise forcing can excite optimal initial conditions that enhance deterministic growth and, thus, improve the predictability of an event. However, the same stochastic forcing may reduce the predictability of the event if it excites the growth of prediction errors after the forecast is initialized or perturbs the state of the tropical Pacific away from expected ENSO growth.

The analysis herein is strongly motivated by the results of Newman and Sardeshmukh (2017), who show that forecasts of tropical Indo-Pacific SST anomalies using LIM have comparable skill to multimodel ensemble mean forecasts made using the full nonlinear coupled ocean-atmosphere models of the North American Multimodel Ensemble (NMME; Kirtman et al. 2014). Both forecast techniques have spatial and temporal variations of skill that are similar both to each other and to the potential skill estimated from the forecast signalto-noise ratios within a perfect linear inverse model framework. This suggests that the deterministic evolution of ENSO evolution can be estimated by a linear approximation to the dynamics. As such, the linear inverse model can be used as a "filter" to remove the deterministic component and, hence, to diagnose the role of noise in the evolution of individual ENSO events; this is not easily accomplished using the full nonlinear GCMs. Following the methods outlined in Penland and Hartten (2014), we empirically calculate the noise forcing conducive to $\mathrm{CP}$ and EP growth directly from observations. We then identify the physical mechanisms within the noise forcing that lead to $\mathrm{CP}$ or EP growth and estimate the role of noise forcing during the 1982/83 and 1997/98 EP ENSO events, the 2009/10 CP ENSO event, the 2015/16 ENSO event, and the "failed" event of 2014. The implications for CP and EP ENSO predictability will be discussed.

This paper is organized as follows. Section 2 of this paper describes the methods for empirically estimating the linear dynamics of the tropical Pacific from observations, the optimal initial conditions that maximize $\mathrm{CP}$ and EP growth. Section 3 explains the methodology for calculating the noise forcing of the CP and EP optimal initial conditions and presents the structures within the noise forcing that lead to CP and EP growth. Section 4 analyzes the role of the noise forcing and dynamics during past CP and EP ENSO events. Section 5 discusses the implications of the results.

\section{Methods}

\section{a. Data}

The linear inverse model is developed using monthly optimally interpolated SST (OISST; Reynolds et al. $2002)$ in the tropical Pacific $\left(25^{\circ} \mathrm{S}-25^{\circ} \mathrm{N}, 120^{\circ}-285^{\circ} \mathrm{E}\right)$ and monthly thermocline depth, calculated as the depth of the $20^{\circ}$ isotherm (Z20) from the NCEP Global Ocean Data Assimilation System (GODAS; Behringer and Xue 2004), between $25^{\circ} \mathrm{S}-25^{\circ} \mathrm{N}$ and $120^{\circ}-285^{\circ} \mathrm{E}$. The SST and Z20 data, from 1982 to 2016 , are averaged onto $2^{\circ}$ latitude $\times 5^{\circ}$ longitude grids. The annual cycle for each dataset is removed by subtracting the 1982-2016 monthly climatological mean from each month. The monthly anomalies are then smoothed with a 3-month running mean and detrended using linear regression. We note that Vimont et al. (2014) develop a linear inverse model using the HadISST product (Rayner et al. 2003) and SODA reanalysis (Carton and Giese 2008), and recover the same results as shown in Fig. 1.

EOF analysis is applied as a prefilter to the monthly SST and Z20 anomalies, so that our analysis is done in the space of the leading nine SST EOFs and three Z20 EOFs. For reference, the leading two EOFs of SST and Z20 are shown in Figs. S1a-d in the online supplemental material. The leading EOF of SST (explaining $52.1 \%$ of the variance) shows a typical canonical ENSO pattern, while the second EOF (12.1\% of the variance) strongly projects onto the SST pattern known as the PMM. For reference, the temporal correlation between the PMM time series and PC2 is $r=0.82$. Supplemental Figs. S1e and S1f show the SST patterns of CP and EP events based upon the Takahashi et al. (2011) definition for the $C$ and $E$ indices as follows:

$$
\begin{aligned}
& C=\left(\frac{\mathrm{PC} 1}{\sqrt{\lambda_{1}}}+\frac{\mathrm{PC} 2}{\sqrt{\lambda_{2}}}\right) / \sqrt{2} \\
& E=\left(\frac{\mathrm{PC} 1}{\sqrt{\lambda_{1}}}-\frac{\mathrm{PC} 2}{\sqrt{\lambda_{2}}}\right) / \sqrt{2},
\end{aligned}
$$

where PC1 is the first principal component of SST, PC2 is the second principal component, and $\lambda_{1}$ and $\lambda_{2}$ are the corresponding eigenvalues. These definitions are used in section $2 b$ to specify the direction of growth in order to estimate the CP and EP optimal initial conditions.

SST pentad means are calculated from daily OISST data from 1982 to 2016 . The Z20 pentad means are calculated from daily GODAS thermocline depths from 1982 to 2016 (again, the thermocline depth is calculated as the depth of the $20^{\circ}$ isotherm). Both SST and Z20 pentad data are averaged onto the same $2^{\circ}$ latitude $\times 5^{\circ}$ longitude 


\section{a. CP Optimal}

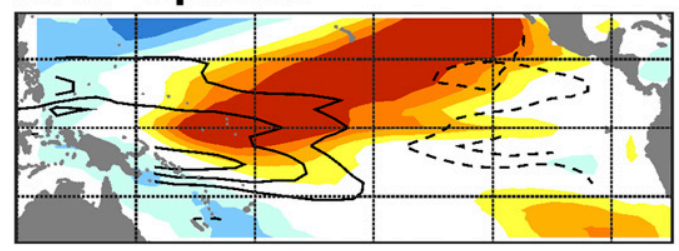

\section{EP Optimal}

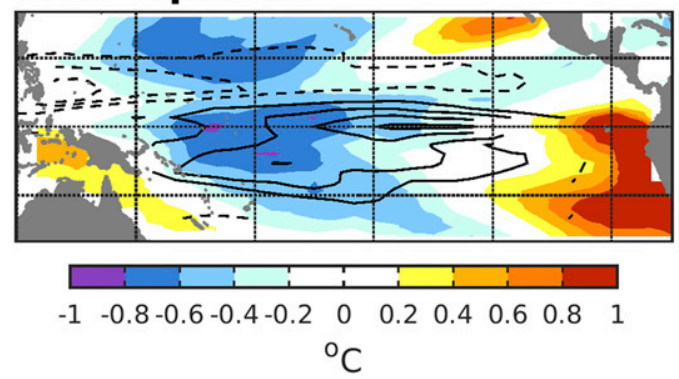

b. CP Final

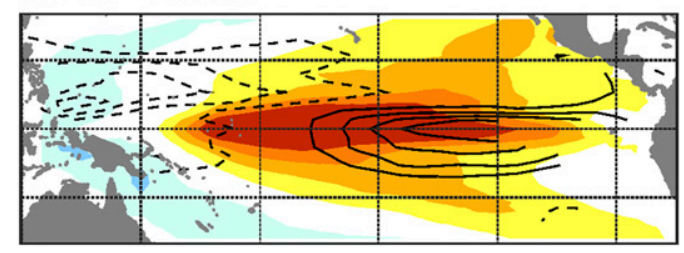

\section{d. EP Final}

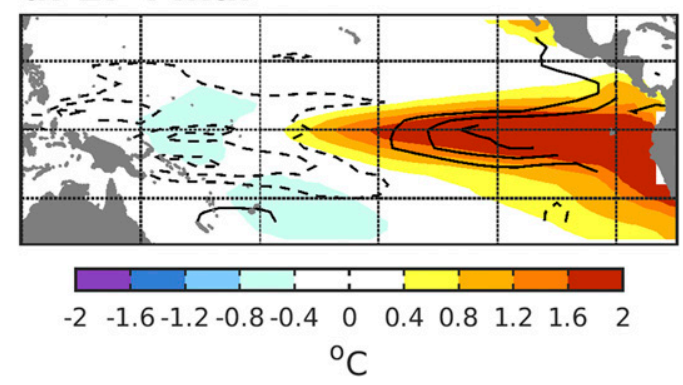

FIG. 1. SST $\left({ }^{\circ} \mathrm{C}\right.$; shading) and thermocline depth (m; black contours) for $\tau=6$ month CP and EP (a),(c) optimal initial conditions and (b),(d) final states. SST contour interval is $0.4^{\circ} \mathrm{C}$ for the optimals and $0.8^{\circ} \mathrm{C}$ for the final conditions. Thermocline depth contour interval is $4 \mathrm{~m}$ for the optimals and $8 \mathrm{~m}$ for the final conditions. Positive (negative) thermocline depth anomalies correspond to solid (dashed) contours. The zero contour has been omitted.

grid as the monthly data. The annual cycle is removed, the data detrended and smoothed with a five-pentad running mean (see section 3b). Similarly, pentad means of several different global quantities are calculated from daily NCEP-NCAR Reanalysis 1 data (Kalnay et al. 1996) between 1982 and 2016. To determine anomalies, the annual cycle is removed and the data detrended for each variable.

\section{b. Linear inverse model}

LIM approximates the evolution of a dynamical system, in this case the tropical Pacific, by a multivariate linear model as follows (Penland and Sardeshmukh 1995):

$$
\frac{d \mathbf{x}}{d t}=\mathbf{L x}+\boldsymbol{\xi}
$$

where $\mathbf{x}$ is the anomalous state of the system, $\mathbf{L}$ is the dynamical system matrix representing the linearized approximation to the dynamics of the system (including the linear approximation to the nonlinear dynamics), and $\boldsymbol{\xi}$ is the white noise forcing. The dynamical system matrix $\mathbf{L}$ can be empirically estimated from a set of observations as presented below, and an empirical estimation of the noise forcing $\boldsymbol{\xi}$ is presented in section $2 \mathrm{~b}$. Previous studies show the tropical Pacific is well represented by this stochastically forced linear system (Penland and Sardeshmukh 1995; Penland 1996). Within this linear inverse model framework, the evolution of the state $\mathbf{x}$ can be described as

$$
\mathbf{x}(t)=e^{\mathbf{L}\left(t-t_{0}\right)} \mathbf{x}\left(t_{0}\right)+\int_{t_{0}}^{t} e^{\mathbf{L}(t-s)} \boldsymbol{\xi}(s) d s,
$$

where the first term on the right-hand side of the equation represents the deterministic, or predicable, evolution of the system from time $t_{0}$ to $t$ (see, e.g., Chang et al. 2004) and the second term represents the nondeterministic, unpredictable, or noise forced, part of the system. Note that the second term convolves the stochastic forcing in (2) with the deterministic dynamical evolution through the remaining forecast time. If the linear model perfectly represents the system, the second term is equal to the forecast error.

It can be shown that the correlation between $\mathbf{x}(0)$ and the second term of (3) is zero. We define $\mathbf{G}_{\tau}$ the "Green function" or propagator matrix as the matrix yielding the linear inverse model forecast $\mathbf{x}^{\prime}(\tau)$ when operating on initial conditions $\mathbf{x}(0)$ :

$$
\mathbf{x}^{\prime}(\tau)=e^{\mathbf{L} \tau} \mathbf{x}(0) \equiv \mathbf{G}_{\tau} \mathbf{x}(0),
$$

where $\mathbf{x}^{\prime}(\tau)$ is the forecast of the final state at time $\tau$ and $\mathbf{x}(0)$ is the initial state. From (4), one can derive $\mathbf{G}_{\tau}$ and $\mathbf{L}$ from the lagged covariance statistics of the system:

$$
\begin{aligned}
\mathbf{G}_{\tau} & =\mathbf{C}_{\tau} \mathbf{C}_{0}^{-1} \quad \text { and } \\
\mathbf{L} & =\ln \left(\mathbf{G}_{\tau}\right) / \tau,
\end{aligned}
$$

where $\mathbf{C}_{\tau}$ is the $\tau$-lag covariance matrix of the state vector $\mathbf{x}$ and $\mathbf{C}_{0}$ is the zero-lag covariance matrix of the 
state vector $\mathbf{x}$. As previously mentioned, the linear operator $\mathbf{L}$ governs the deterministic evolution of the system over a specific time period $\tau$. The maximum amplification (e.g., Penland and Sardeshmukh 1995, Fig. 4) curve indicates that the system experiences maximum growth over a time period of about 9 months. The growth curve of the error energy intersects the maximum amplification curve around 23 months, which represents the predictability limit of the system (results not shown).

We define the state vector $\mathbf{x}$ as in Vimont et al. (2014) with sea surface temperature (SST) and thermocline depth (Z20) as follows:

$$
\mathbf{x}=\left(Z_{\mathrm{SST}}, Z_{\mathrm{Z} 20}\right)
$$

where $Z_{\text {SST }}$ represents the leading nine SST principal components (PCs) $\left(88.1 \%\right.$ of the variance) and $Z_{\mathrm{Z} 20}$ the leading three Z20 PCs ( $45.8 \%$ of the variance). The PCs of the state vector are normalized by the square root of the total variance of the respective field; that is, $Z_{\mathrm{SST}}$ is normalized by the square root of the sum of all SST eigenvalues, and $Z_{\mathrm{Z} 20}$ is normalized by the square root of the sum of all Z20 eigenvalues.

\section{c. Optimal initial conditions}

The noise forcing that will maximize the deterministic growth toward CP or EP events will be the noise that pushes the system toward generating the associated optimal initial conditions. Therefore, we first calculate the optimal initial conditions that maximize either CP or EP growth. Using the previously calculated linear dynamics of the system (6), we are able to determine the initial state that maximizes the deterministic growth in a given direction (Penland and Sardeshmukh 1995; Newman et al. 2011a; Vimont et al. 2014). The resulting initial structures are, hereafter, referred to as optimal initial conditions. The optimal initial conditions that maximize growth toward the $\mathrm{CP}$ and $\mathrm{EP}$ final conditions are calculated by following the methodology of Vimont et al. (2014). Based upon the definition of CP and EP events (1), we define the vector coordinate directions for the $\mathrm{CP}$ and $\mathrm{EP}$ events as follows:

$$
\begin{aligned}
& \mathbf{n}_{\mathrm{CP}}=\left\{\frac{1}{\sqrt{2 \lambda_{1}}}, \frac{1}{\sqrt{2 \lambda_{2}}}, 0,0, \ldots\right\} \\
& \mathbf{n}_{\mathrm{EP}}=\left\{\frac{1}{\sqrt{2 \lambda_{1}}},-\frac{1}{\sqrt{2 \lambda_{2}}}, 0,0, \ldots\right\},
\end{aligned}
$$

where $\lambda_{1}$ and $\lambda_{2}$ are the leading two SST eigenvalues. The CP and EP final norm kernels $(N)$, which define the direction of growth, are defined as

$$
\begin{aligned}
& N_{\mathrm{CP}}=\mathbf{n}_{\mathrm{CP}}^{\mathrm{T}} \mathbf{n}_{\mathrm{CP}}+\epsilon \mathbf{l} \\
& N_{\mathrm{EP}}=\mathbf{n}_{\mathrm{EP}}^{\mathrm{T}} \mathbf{n}_{\mathrm{EP}}+\epsilon \mathbf{l},
\end{aligned}
$$

where $\epsilon \mathrm{l}$ is the identity matrix times some arbitrary small number $\left(\epsilon=10^{-9}\right)$ that is necessary for numerical stability (Tziperman et al. 2008). Using the CP and EP norms above, we estimate the optimal initial conditions $\mathbf{p}$ that maximize growth $\mu$ in the direction of the chosen norm $N$ over a finite time period $\tau$ by solving the generalized eigenvalue problem:

$$
\mathbf{G}_{\tau}^{\mathrm{T}} N \mathbf{G}_{\tau} \mathbf{p}-\mu(\tau) \mathbf{p}=0 .
$$

Figures $1 \mathrm{a}$ and $1 \mathrm{c}$ show the optimal initial conditions that maximize either CP or EP growth, respectively, over a 6-month time period. Results are similar for $\tau=3$ months and $\tau=9$ months (not shown). The final CP and EP ENSO states are shown in Figs. 1b and 1d, respectively. Optimal initial and associated final conditions found here are very similar to those previously calculated in Vimont et al. (2014); we show the structures here since the linear inverse model in this study is constructed with different SST and thermocline datasets. The optimal initial conditions maximizing CP growth show a spatial SST structure representative of the PMM, along with an increased zonal thermocline gradient with deep thermocline anomalies in the western Pacific and shoaled thermocline anomalies in the eastern Pacific. The EP optimal initial conditions contain a zonal SST gradient containing positive SST anomalies located in the far eastern Pacific and negative SST anomalies in the western and central Pacific. The EP optimal conditions also suggest that a deepened thermocline across much of the central equatorial Pacific maximizes EP growth. The optimal structures are insensitive to the number of EOFs retained in the state vector, which is consistent with the results from Vimont et al. (2014).

The temporal evolution patterns of the L2 (i.e., the Euclidean norm), CP, and EP optimal initial conditions (red lines) together with SST PC1 and the CP and EP indices (black lines) are shown in Figs. 2a-c. The time series of the optimal initial conditions are calculated by projecting the state vector $\mathbf{x}$ (7) onto the $\mathrm{L} 2, \mathrm{CP}$, or EP optimal initial structures. As expected, the L2, CP, and EP optimal initial time series lead the SST PC1, CP index, and EP index, respectively. The maximum lagged correlation for both $\mathrm{CP}$ and EP occurs when the optimal leads the index by 2 months.

\section{Noise forcing of CP/EP optimals}

This section describes the methods used to estimate the noise forcing that drives the tropical Pacific toward a 
a. SST PC1 and L2 Optimal

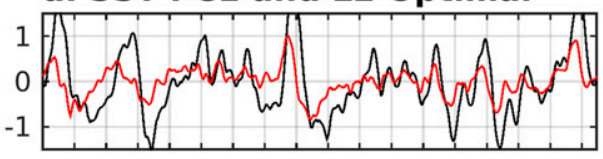

b. CP Index and CP Optimal

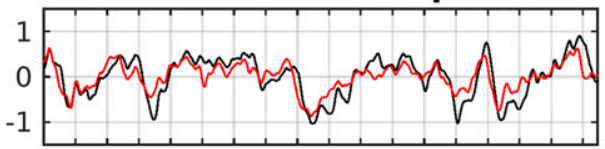

c. EP Index and EP Optimal
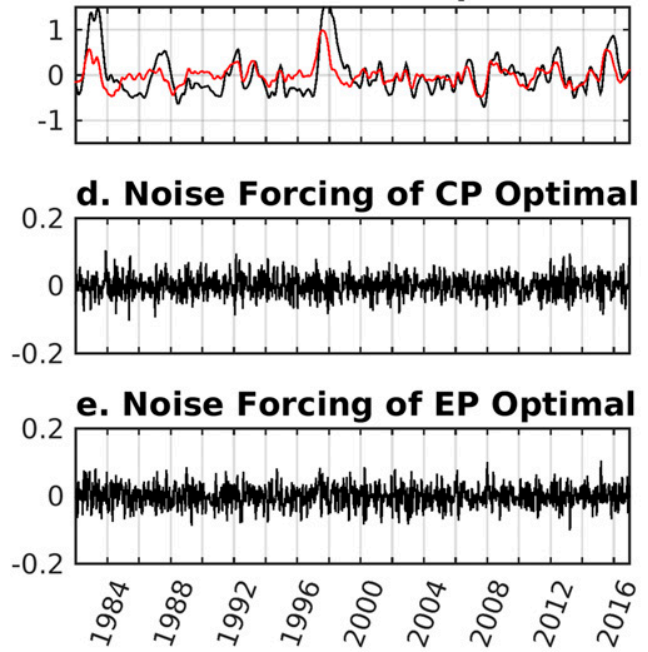

f. Total Noise Variance
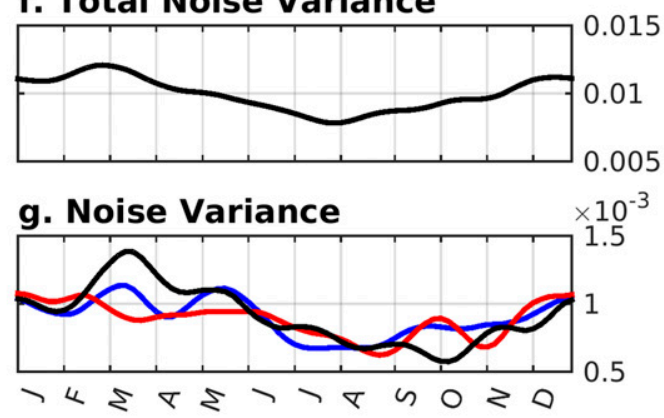

h. CP Noise Power Spectra

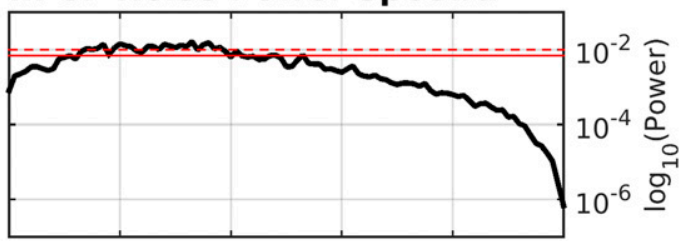

i. EP Noise Power Spectra

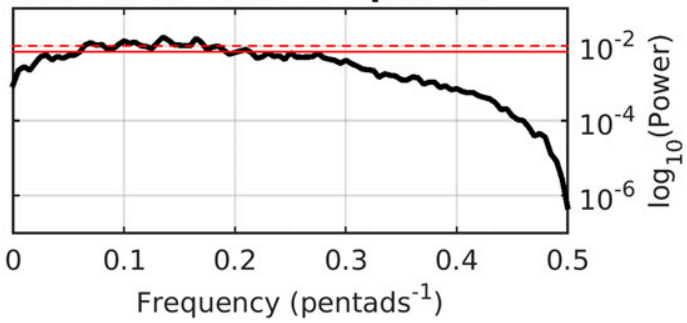

FIG. 2. The temporal evolution of (a) SST PC1 (black) and L2 optimal initial conditions (red), (b) CP index (black) and CP optimal initial conditions (red), and (c) EP index (black) and EP optimal initial conditions (red). The noise forcing time series associated with 6-month (d) CP and (e) EP optimal initial conditions are shown. The $\mathrm{CP}$ and EP noise forcing time series in (d) and (e) are calculated as the projection of $\xi(t)$ [see (11)] onto the CP or EP optimal initial conditions (Fig. 1). (f) The seasonal variance of the total noise forcing $\xi(t)$ is shown as is (g) the seasonal variance of the noise forcing associated with the L2 (blue), CP (red), and EP (black) optimals. The variance is smoothed with successive five- and seven-pentad running means. The power spectra (solid black) of the unfiltered (h) CP and (i) EP noise forcing time series. The solid red lines show the white noise null hypothesis, while the dashed red lines show the $95 \%$ confidence interval.

particular state, especially the optimal initial conditions for CP or EP ENSO events. We then diagnose specific physical mechanisms that contribute to that noise forcing.

\section{a. Stochastic forcing}

The observed stochastic forcing, or noise forcing, of the system [see (2)] can be estimated using a centereddifference approximation to (2) following the methodology described in Penland and Hartten (2014):

$$
\boldsymbol{\xi}(t) \approx \frac{[\mathbf{x}(t+\Delta t)-\mathbf{x}(t-\Delta t)]}{2 \Delta t}-\mathbf{L x},
$$

where $\mathbf{x}$ is now the finely resolved (in time) state vector based on pentad data and $\mathbf{L x}$ is the deterministic evolution. Note here that the right-hand side of (11) can be interpreted as a "dynamical filter" that removes the deterministic tendency ( $\mathbf{L x}$ ) from the actual tendency. The result (left-hand side) is an estimate of the broadband forcing that the slow dynamics will see as white at the frequencies of interest to El Niño (see Figs. 2h,i). The resulting multivariate time series $\boldsymbol{\xi}(t)$ empirically estimates the nondeterministic component of the system's tendency (i.e., the noise forcing) and not the deterministic evolution of ENSO itself. This is critical to ensuring that the resulting noise patterns are not simply aliasing the deterministic component of ENSO's evolution. In other words, because (i) the linear inverse model largely reproduces both seasonal and year-toyear variations of tropical Indo-Pacific SST forecast skill from fully nonlinear models (see Figs. 2 and 3 in Newman and Sardeshmukh 2017) and (ii) the linear inverse model describes the deterministic evolution of 
the system, we can use (11) to filter out the deterministic component, thereby retaining the nondeterministic contribution from the noise.

Note that although we have calculated $\mathbf{L}$ from monthly (i.e., coarse grained) data, in (11) we estimate the noise from pentad (i.e., more finely resolved) data. The reason for this distinction is described in the cautionary note from Penland and Hartten (2014; see the supplemental material therein) on the centered difference approximation to the continuous Stratonovich system in (2). In a Stratonovich system the contemporaneous correlation between the noise and the system state is nonzero, and the centered-difference equation approximation in (11) is only valid in the limit as $\Delta t$ goes to zero. In this case, the approximation is justified if the time scale over which (11) is evaluated is short compared to that of the deterministic evolution of the system. Hence, we evaluate (11) using pentad data. Additionally, we have confirmed that the noise covariance matrix estimated from (11) is consistent with the noise covariance matrix calculated using the fluctuation-dissipation relationship with stationary statistics (Penland and Sardeshmukh 1995; for further details see section S2a in the online supplemental material).

The finely resolved state vector $\mathbf{x}$ is defined as the projection of the pentad SST and Z20 anomalies onto the leading nine SST and three Z20 EOFs that were identified from monthly data (see section 2a). As before, these time series (nine SST and three Z20) of the finely resolved state vector $\mathbf{x}$ are normalized by the square root of the total variance of each variable's monthly anomalies. Finally, the pentad-evolving multivariate noise is estimated as a residual from (11), resulting in a multivariate dataset with 12 degrees of freedom (nine SST and three Z20) and 2555 pentads $(73 \times 35 \mathrm{yr}$ of data $)$.

\section{b. Noise structures associated with CP and EP optimals}

The noise time series associated with forcing any specified optimal initial conditions is estimated by projecting the total noise forcing $\boldsymbol{\xi}(t)$ in (11) onto that optimal's spatial structure. Figures $2 \mathrm{~d}$ and $2 \mathrm{e}$ show the resulting time series of noise forcing associated with the $\mathrm{CP}$ and $\mathrm{EP}$ 6-month optimals, respectively. A Kolmogorov-Smirnov test applied to both noise time series shows their distributions are not significantly non-Gaussian (section S2c in the supplemental material). The linear inverse model assumes that relative to its deterministic time scales, the noise forcing will be spectrally white, which is confirmed by the spectral analysis of the raw noise in Figs. $2 \mathrm{~h}$ and $2 \mathrm{i}$. Further details regarding the evaluation of the spectral behavior of the noise are provided in the supplemental material (section S2b). The decrease in power at high frequencies is expected due to the centered-differencing method used to estimate the noise. Due to this characteristic, we apply a five-pentad running mean to the SST and Z20 data prior to calculating the noise time series to remove the insignificant high-frequency variance in the noise. Several previous studies also show the low-frequency part of the noise spectrum is more effective in forcing ENSO (Roulston and Neelin 2000; Newman et al. 2009; Levine and Jin 2010; Lopez et al. 2013).

Figure $2 \mathrm{f}$ shows the seasonal variation of the total noise forcing amplitude, which reaches a maximum (minimum) during March (August). Figure 2g shows the seasonal variation of the noise amplitudes associated with the L2 (blue), CP (red), and EP (black) optimals. The variance was smoothed with successive five- and seven-pentad centered running means. CP noise amplitudes have the weakest seasonality but are highest during boreal winter (DJF). The EP noise variance, on the other hand, contains much stronger seasonality and is highest during boreal spring (MAM) and lowest during fall (SON). Unlike Penland (1996), there is no semiannual seasonal cycle in the noise variance, likely because of the inclusion of subsurface data in this analysis.

To identify physical mechanisms within the stochastic forcing contributing to $\mathrm{CP}$ and EP optimal initial condition development, we regress the global pentad-averaged anomalies onto the stochastic forcing time series in Figs. $2 \mathrm{~d}$ and $2 \mathrm{e}$. The resulting regression maps, shown for each season in Figs. 3 and 4, may be interpreted as variability in a particular field that covaries with the noise forcing of a given set of optimal initial conditions and are robust to modifications of the number of EOFs retained in the state vector. While this technique does not necessarily identify specific mechanisms that guarantee ENSO growth, it does identify atmospheric patterns that covary with the noise forcing of the $\mathrm{CP}$ and EP optimals. These patterns are consistent with a number of mechanisms previously proposed in the literature, as discussed below. See the supplemental material for full regression maps and a discussion of the statistical significance.

Figure 3 shows sea level pressure (SLP), 850-mb wind, and outgoing longwave radiation (OLR) anomalies regressed on the noise forcing time series associated with the 6-month CP (left column) and EP (right column) optimal initial conditions. Figure 4 shows the corresponding regression patterns of ocean-atmosphere thermal flux (OAFLUX, defined as sensible heat flux + latent heat flux; positive upward) and surface wind stress anomalies. Note that the maps in Figs. 3 and 4 contain a large range of variabilities, which is not surprising considering that "noise forcing" could include a variety of phenomena. 

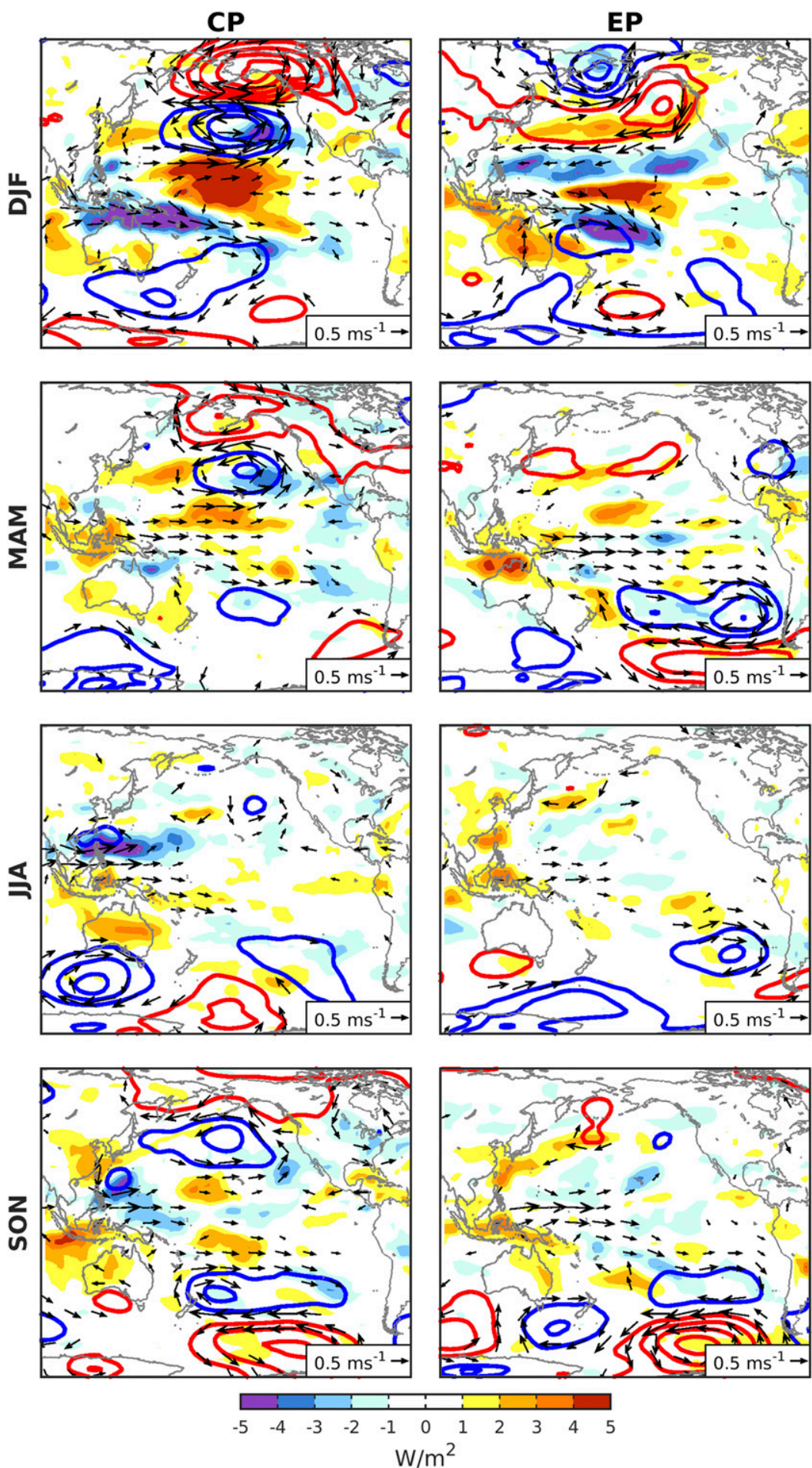

FIG. 3. Atmospheric noise structures associated with (left) CP and (right) EP optimal initial conditions. Shown are the seasonal regression coefficients between sea level pressure (SLP; $\mathrm{hPa}$; contours), 850-mb wind ( $\mathrm{m} \mathrm{s}^{-1}$; vectors), and OLR $\left(\mathrm{W} \mathrm{m}^{-2}\right.$; shading), as well as the noise forcing time series of the CP or EP optimal initial conditions. The first row shows the regression coefficients of boreal winter (DJF). The second through fourth rows show the regression coefficients for the boreal spring (MAM), summer (JJA), and fall (SON) months, respectively. Positive (negative) SLP is indicated with red (blue) contours where the contour interval is every $0.5 \mathrm{hPa}$. The zero contour has been omitted. OLR is defined as positive upward. Wind vectors are only shown where the geometric sum of the correlation coefficients is equal to or greater than 0.1 . 

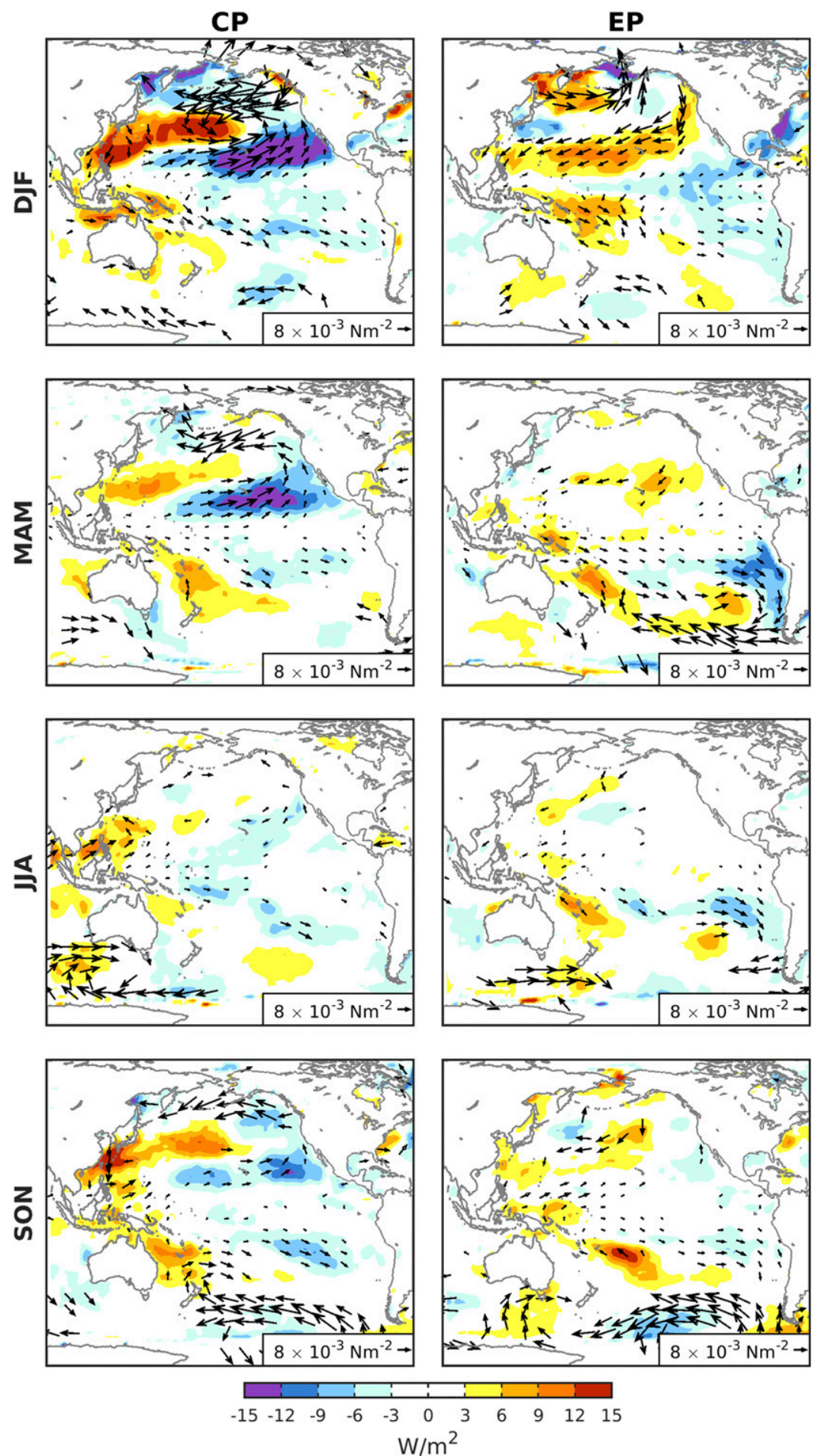

FIG. 4. Noise-forced oceanic structures associated with (left) CP and (right) EP optimal initial conditions. Shown are the seasonal regression coefficients between the surface wind stress ( $\mathrm{N} \mathrm{m}^{-2}$; vectors) and ocean-atmosphere flux (OAFLUX; $\mathrm{W} \mathrm{m}^{-2}$; shading) and the noise forcing time series of the CP or EP optimal initial conditions. The first row shows the regression coefficients of boreal winter (DJF). The second through fourth rows show the regression coefficients for the boreal spring (MAM), summer (JJA), and fall (SON) months, respectively. OAFLUX is defined as positive upward. Wind stress vectors only shown where the geometric sum of the correlation coefficients is equal to or greater than 0.1 . 
The CP SLP structures (Fig. 3, left) show typically higher noise amplitudes during winter and spring in each hemisphere. In the Northern Hemisphere, the CP SLP forcing structures during boreal fall (SON), winter (DJF), and spring (MAM) are similar to those of the North Pacific Oscillation (NPO). During these seasons, the OAFLUX (Fig. 4, left) shows a flux into the ocean with a pattern corresponding to the PMM. These results support previous studies that show the NPO and PMM are related to initiating CP ENSO events ( $\mathrm{Yu}$ and Kim 2011; Kim et al. 2012b). In the Southern Hemisphere, subtropical SLP anomalies contribute to CP noise forcing throughout the year, associated with only weak downward heat flux anomalies.

For forcing the EP optimal, on the other hand, the Northern Hemisphere SLP noise is much less important except perhaps during winter, whereas the Southern Hemisphere SLP noise appears important throughout the year (Fig. 3, right). In particular, a dipolar SLP structure is evident during austral fall (MAM) and spring (SON) that resembles the "South Pacific Oscillation," which has been identified as an EP ENSO precursor by You and Furtado (2017). Similar SLP patterns are also found in Penland and Matrosova (2008). The 850-mb wind (Fig. 3, right) and surface wind stress (Fig. 4, right) patterns show positive zonal wind anomalies in the equatorial Pacific throughout the year, although there are slight seasonal differences in the location and magnitude. The zonal winds lie south of the equator in the western tropical Pacific during DJF, centered close to the equator during MAM and JJA, and north of the equator in the western tropical Pacific during SON. The wind anomalies are weakest during boreal summer (JJA). Since the EP noise variance peaks in boreal spring (MAM; Fig. 2f), the springtime noise structures are of particular interest. The springtime (MAM) stochastic forcing of EP optimals shows strong low-level zonal wind anomalies in the western and central tropical Pacific (Fig. 3, right). Interestingly, the ocean-atmosphere flux shows a flux into the ocean in the Southern Hemisphere off the South American coast from DJF through JJA (Fig. 4, right), suggestive of the South Pacific meridional mode (SPMM).

\section{Role of noise forcing versus deterministic dynamics during past ENSO events}

In the previous section, we identified noise structures related to the excitation of an optimal set of initial conditions, which will lead to maximum deterministic growth [first term on the right-hand side of (3)] over some time period. In this section, over the lifetime of different
ENSO events, we compare the deterministic evolution from initial conditions to the nondeterministic evolution driven by noise. We note that the nondeterministic evolution of the system is controlled by the second term in (3). Chang et al. (2004) show that the forcing structure optimizing error growth over a finite time period (time 0 to $\tau)$ is the leading eigenvector of $\mathbf{B}(\tau)$, where

$$
\mathbf{B}(\tau)=\int_{0}^{\tau} e^{\mathbf{L} *(\tau-s)} e^{\mathbf{L}(\tau-s)} d s .
$$

It is worth noting the relationship between the initial optimals investigated in section 3 and the noise structures that dominate the nondeterministic trajectory. At a given time $\tau^{\prime}$ after the forecast initialization, but before a forecast target end time $\tau$, the relationship between the initial optimals and the optimal noise structure can be illuminated by writing (12) as an infinite sum:

$$
\mathbf{B}(\tau)=\lim _{n \rightarrow \infty}\left[\sum_{k=1}^{n} e^{\mathbf{L} *(\tau-k \delta s)} e^{\mathbf{L}(\tau-k \delta s)} \delta s\right]
$$

(where $\delta s=\tau / n$ ). Note that at time $\tau^{\prime}$ the argument inside the sum is simply $\mathbf{G}_{\tau-\tau^{\prime}}^{\mathrm{T}} \mathbf{G}_{\tau-\tau^{\prime}}$. Hence, the structure that optimally perturbs a system away from its trajectory at time $\tau^{\prime}$ between 0 and $\tau$ is simply the optimal set of initial conditions at time $\tau-\tau^{\prime}$. That is, at some time $\tau^{\prime}$ after the forecast initialization, the noise structure that optimally ruins a forecast is that which experiences the most transient growth over the remaining forecast time $\left(\tau-\tau^{\prime}\right)$. This argument can easily be generalized to investigate growth toward or away from specific norms, and is used to investigate the role of noise forcing in the generation of ENSO events with specific CP or EP characteristics herein. We use the 6-month optimal initial structure for analysis herein; results are not sensitive to the choice of optimization time.

To highlight how the role of the noise forcing can vary for any given event, we select two strong EP events (1982/83 and 1997/98), one strong CP event (2009/10), the recent 2015/16 event (which displays both CP and EP characteristics), and the "failed" 2014 event. The relative role of (i) deterministic evolution from initial conditions versus (ii) stochastic forcing is evaluated by integrating the model forward in time with either (i) the deterministic component only [first term on the righthand side of (3); noise set to zero] or (ii) the stochastic noise component only [second term on the right-hand side of (3); initial state set to zero]. Comparing the observed SST anomalies with (i) the SST predicted by the deterministic component or (ii) the noise-forced SST evolution allows us to estimate the relative importance of the noise forcing and deterministic dynamics for any 
given event. Note that since the noise forcing in this study is calculated as a residual, by definition, it contains influences from both the stochastic noise forcing as well as nonlinearities not captured by the linear approximation to nonlinear dynamics. The importance of the timing for the initial conditions and noise forcing is inferred through initializing the linear inverse model (using the two terms above) from different months, determined as the pentad containing the first day of the respective month.

LIM also allows us to determine how CP and EP noise forcing impacted each event. Similar to the method described above, we integrate the linear inverse model forward in time using staggered initial conditions. However, by systematically removing the noise projecting onto either the CP or EP optimal, and comparing the resulting SST forecast to the observed SST anomalies, we can determine the importance of CP or EP noise forcing in generating the observed ENSO characteristics. We then quantify how well the LIM without either the CP or EP noise forcing reproduces the observed SST by calculating the root-mean-square error (RMSE) of the $\mathrm{CP}$ index and EP index as follows:

$$
\mathrm{RMSE}=\sqrt{\frac{\sum_{i=1}^{n}\left(X_{\mathrm{LIM}}-X_{\mathrm{Obs}}\right)^{2}}{n}},
$$

where $X_{\text {LIM }}$ is the CP or EP index in (1) for the LIM SST forecast without CP or EP noise forcing, respectively; $X_{\mathrm{Obs}}$ is the CP or EP index of the observed SST; and $n$ is the number of pentads. The RMSE is calculated between the initialization (the first pentad of each month) through the last pentad of the February following the peak of the event. We use both $\mathrm{CP}$ and $\mathrm{EP}$ indices rather than a single ENSO index (such as the Niño-3.4 index) in order to capture the importance of the $\mathrm{CP}$ and EP noise forcing in generating strong EP and $\mathrm{CP}$ spatial characteristics. It is important to note, however, that any given ENSO event may be influenced by stochastic forcing that is characterized by a combination, or complete lack of, $\mathrm{CP}$ and EP forcing.

\section{a. 1982/83 El Niño event}

We first analyze the tropical Pacific SST anomalies from the 1982/83 ENSO event. The Hovmöller diagrams in Fig. 5 show the observed equatorial SST anomalies of the event (top left) and various LIM simulations of the SST anomalies. The remainder of the top row shows the full LIM simulation [calculated using both terms on the right-hand side of (3)], which match the observations well no matter when the model is initialized, as expected [this also serves as a check on the centered differencing in (11)]. The middle row shows the SST anomalies due to the deterministic, or predictable, component of the LIM [first term on the right-hand side of (3)] while the bottom row shows the unpredictable, or noise forced, component, of the SST anomalies [second term on the righthand side of (3)], as explained above. By definition, the dynamical SST anomalies plus the noise-forced SST anomalies equal the SST anomalies produced by the full LIM (i.e., top row $=$ middle row + bottom row). The label at the very top of each column indicates the month of initialization; the model is initialized with observations from the first pentad of the month. The timing of the initialization is indicated in the Hovmöller diagrams with the horizontal black lines, and time increases along the $y$ axis and longitude $\left({ }^{\circ} \mathrm{E}\right)$ are indicated along the $x$ axis.

Figure 5 indicates that deterministic dynamics do a poor job at reproducing the observed SST anomalies for the 1982/83 ENSO event prior to the October initial conditions; instead, noise forcing dominates. Only when the model is initialized in October or later does the dynamical forecast reproduce the peak amplitude of the 1982/83 ENSO event. This suggests the state of the system in October, once the ENSO event has begun, is sufficient for generating a skillful dynamical forecast of the ENSO event, while the state of the tropical Pacific prior to October was insufficient to generate a strong ENSO event without the influence of stochastic forcing. More specifically, these results suggest the noise forcing that occurs after the August initialization but prior to the October initialization is critical for producing the October conditions that generate the large-amplitude SST anomalies at the peak of the 1982/83 ENSO event. Furthermore, once the deterministic dynamics begin to dominate the ENSO development in boreal fall, they also dominate the development of the La Niña event that occurs during the following boreal winter. This shows that the 1983/84 La Niña was a result of deterministic evolution from El Niño conditions in late 1982.

To determine whether the CP or EP noise forcing is more important for the generation of the 1982/83 event, we repeat the LIM simulations, except that we systematically remove the $\mathrm{CP}$ or EP noise forcing from the model and calculate the RMSE of the CP and EP index of the resulting SST "forecast." These results are summarized in the RMSE calculations for the 1982/83 event shown in Fig. 6a. The red plus $(+)$ signs show the CP index RMSE of the LIM run without CP noise forcing, while the black crisscrosses $(\times)$ represent the EP index RMSE of the LIM run without EP noise forcing. The large EP index errors suggest EP noise forcing is critical to the development of the strong EP characteristics observed during the 1982/83 event while CP noise forcing is much less influential (indicated by small RMSE values for the CP 


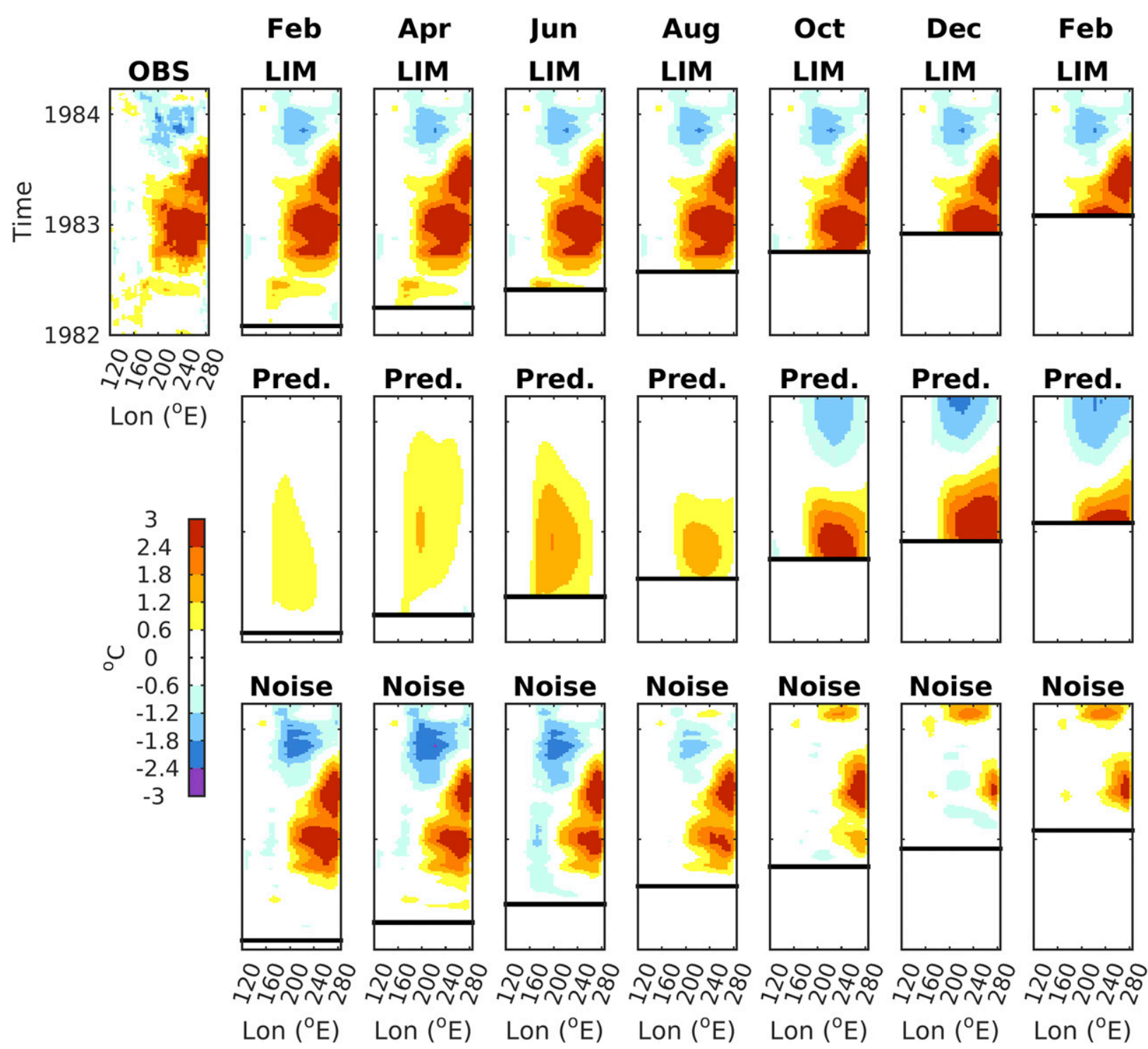

FIG. 5. Hovmöller diagrams of equatorial Pacific $\left(120^{\circ}-285^{\circ} \mathrm{E}\right) \mathrm{SST}$ (averaged from $2^{\circ} \mathrm{S}$ to $\left.2^{\circ} \mathrm{N}\right)$ for the $1982 / 83$ ENSO event. Time increases upward along the $y$ axis and longitude $\left({ }^{\circ} \mathrm{E}\right)$ is indicated along the $x$ axis. The observed SST anomalies are shown at the top left. The remainder of the top row shows the SST anomalies predicted from the full LIM containing both deterministic dynamics and stochastic forcing [calculated using both terms on the right-hand side of (3)]. (middle) The portion of SST anomalies predicted by the deterministic dynamical component [first term on the right-hand side of (3)]. (bottom) The component of the SST anomalies driven by the stochastic forcing term (second term on right-hand side of (3)]. The columns represent initializations every 2 months between February 1982 and February 1983. The LIM is initialized using observations during the first pentad of the indicated month. The month of initialization is listed at the very top of each column and is indicated by the horizontal black lines in the diagrams.

index). These results also show the noise forcing is particularly important during boreal spring and summer. However, the magnitude of the EP errors decreases dramatically when the LIM is initialized in late summer/fall, which supports the previous conclusions that the state of the system during fall is sufficient to develop into an ENSO event through deterministic dynamics alone, while the noise forcing during boreal spring and summer is necessary to generate those conditions.
Finally, we analyze the structures of noise forcing during the key months identified above for the development of the 1982/83 EP El Niño. However, at any given time, a field will contain contributions from the nondeterministic noise, and from deterministic evolution (the coupled evolution of ENSO). As such, the deterministic component needs to be removed. Noise structures in fields that are not included in the state vector $\left[y^{\text {noise }}(x, y, t)\right]$ are identified using multiple linear regression of the pentad NCEP-NCAR reanalysis 

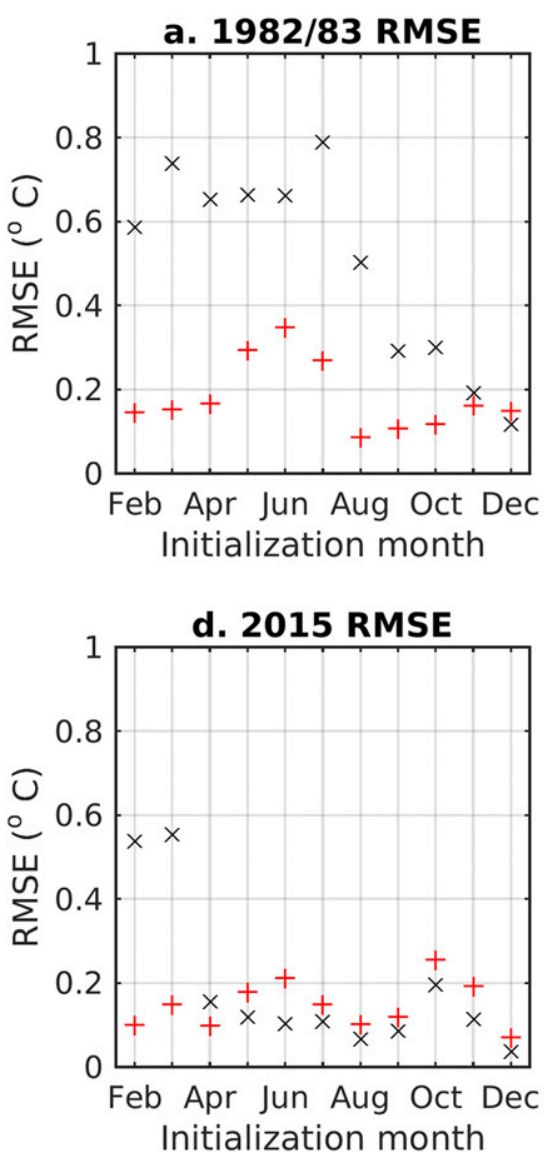

b. $1997 / 98$ RMSE

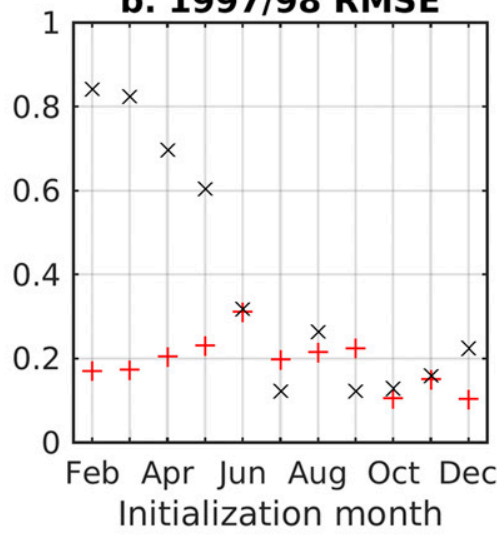

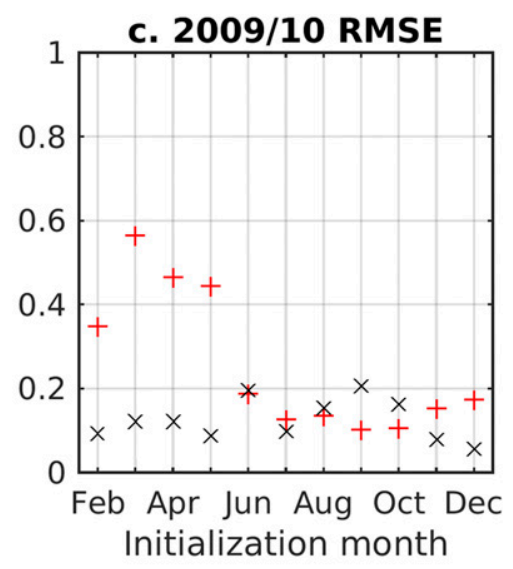

e. 2014 RMSE

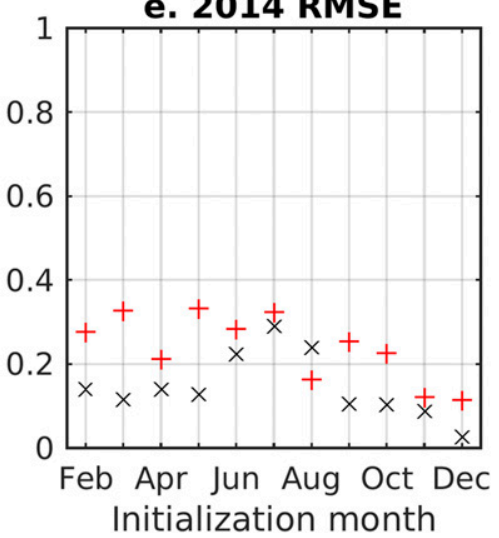

FIG. 6. RMSEs calculated for CP (red + signs) and EP (black $\times$ symbols) indices for the LIM forecasts containing no CP or EP noise forcing, respectively. The RMSE is calculated between the initialization month (indicated along the $x$ axis) through the end of the February following the peak of the event for the (a) 1982/83, (b) 1997/98, (c) 2009/10, and (d) 2015 El Niño events. (e) The RMSE values for the failed 2014 event.

data (from 1982-2016) onto the noise time series $[\boldsymbol{\xi}(t)$ as calculated in (11)]:

$$
y^{\text {noise }}(x, y, t)=\sum_{i=1}^{N} a_{i}(x, y) \xi_{i}(t),
$$

where $a_{i}(x, y)$ are the multiple regression coefficients. For each spatial point in a given field, we use multiple linear regression to predict the full (1982-2016) time evolution of the pentad data. The resulting dataset contains variability that covaries with the nondeterministic component of the system: the noise. We then analyze the monthly mean noise patterns for the specific months of interest during the development of each ENSO event. Figure 7 shows the monthly mean, uncoupled SLP (contours), 850-mb wind (vectors), and OAFLUX (shading) anomalies for July-October 1982. Since the October 1982 initial conditions are sufficient for generating ENSO growth through deterministic dynamics alone, we primarily focus on the stochastic forcing patterns in the months prior to October. The July, August, and September noise patterns show strong positive zonal wind anomalies located in the western equatorial Pacific. These zonal wind anomalies extend across much of the equatorial Pacific during September 1982. These westerly wind structures also match the JJA and SON EP noise forcing patterns in Fig. 3.

\section{b. 1997/98 El Niño event}

We next analyze the atmospheric noise patterns that occur during the development of the 1997/98 EP El Niño. Figure 8 shows the same LIM simulations as Fig. 4, but for the 1997/98 El Niño. Unlike the 1982/83 EP event, which appears to have been largely influenced by noise forcing in late boreal summer, the Hovmöller diagrams in Fig. 8 show that the deterministic dynamics of the LIM reproduce the observed evolution of the 1997/98 El Niño more accurately from much earlier initializations. This agrees with previous studies that also show a relatively long predictability of the 

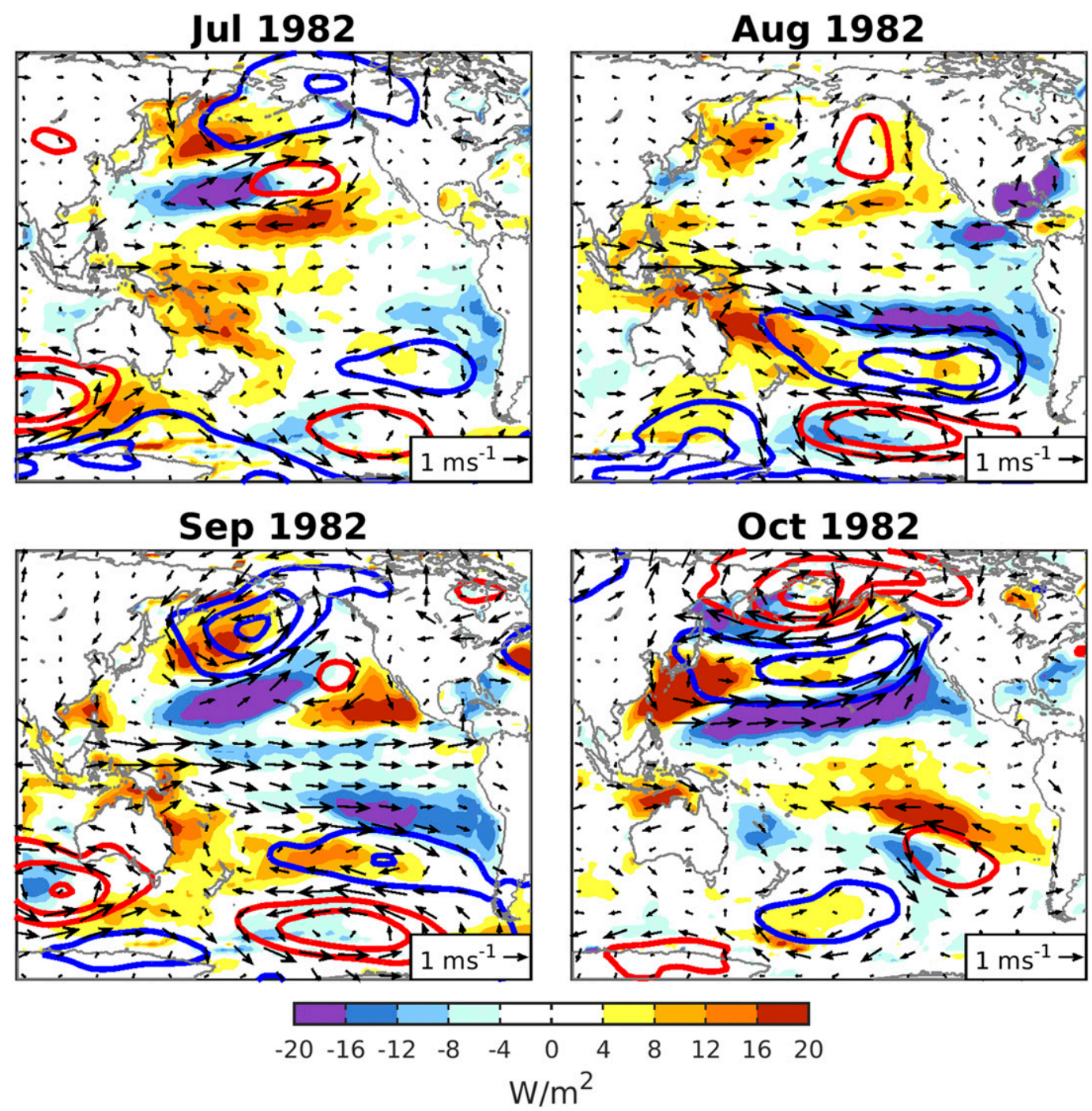

FIG. 7. Monthly mean noise structures for July-October 1982. SLP anomalies (hPa; contours), 850-mb wind anomalies ( $\mathrm{m} \mathrm{s}^{-1}$; vectors), and OAFLUX anomalies $\left(\mathrm{W} \mathrm{m}^{-2}\right.$; shading) are shown. Positive (negative) SLP anomalies are indicated with red (blue) contours where the contour interval is every $1 \mathrm{hPa}$. The zero contour has been omitted. OAFLUX fluxes are defined as positive upward.

1997/98 event (Newman and Sardeshmukh 2017). Our results show this is especially true when the LIM is initialized in June or later. Indeed, beyond June the noise forcing has little to no effect on the amplitude of the equatorial SST anomalies during the ensuing El Niño event, though they do contribute to a more rapid decay of the event and transition toward the 1998/99 La Niña.

Next, we determine if the noise forcing of the 1997/98 event is dominated by CP or EP noise. These results are shown in Fig. 6b, which shows the RMSE of the CP and EP index from the LIM forecasts without CP or EP noise forcing, respectively. Again, the RMSE is calculated from the model initialization date through the end of the February following the peak of the warming. The LIM without CP noise forcing reproduces the observed event well, as indicated by the small magnitudes of the CP index RMSE (Fig. 6b; red plus signs), indicating CP noise forcing is not important in the development of the 1997/98 event. The EP noise forcing, on the other hand, appears to be much more important to the development of the event, especially early in the year. The large RMSE of the EP index for the LIM forecast without EP noise forcing (Fig. 6b; black ×s) through May 1997 shows the importance of EP noise forcing early in the year; however, the magnitude of the errors decreases drastically beginning in early boreal summer. The sharp decrease in RMSE that occurs after May 1997 indicates 


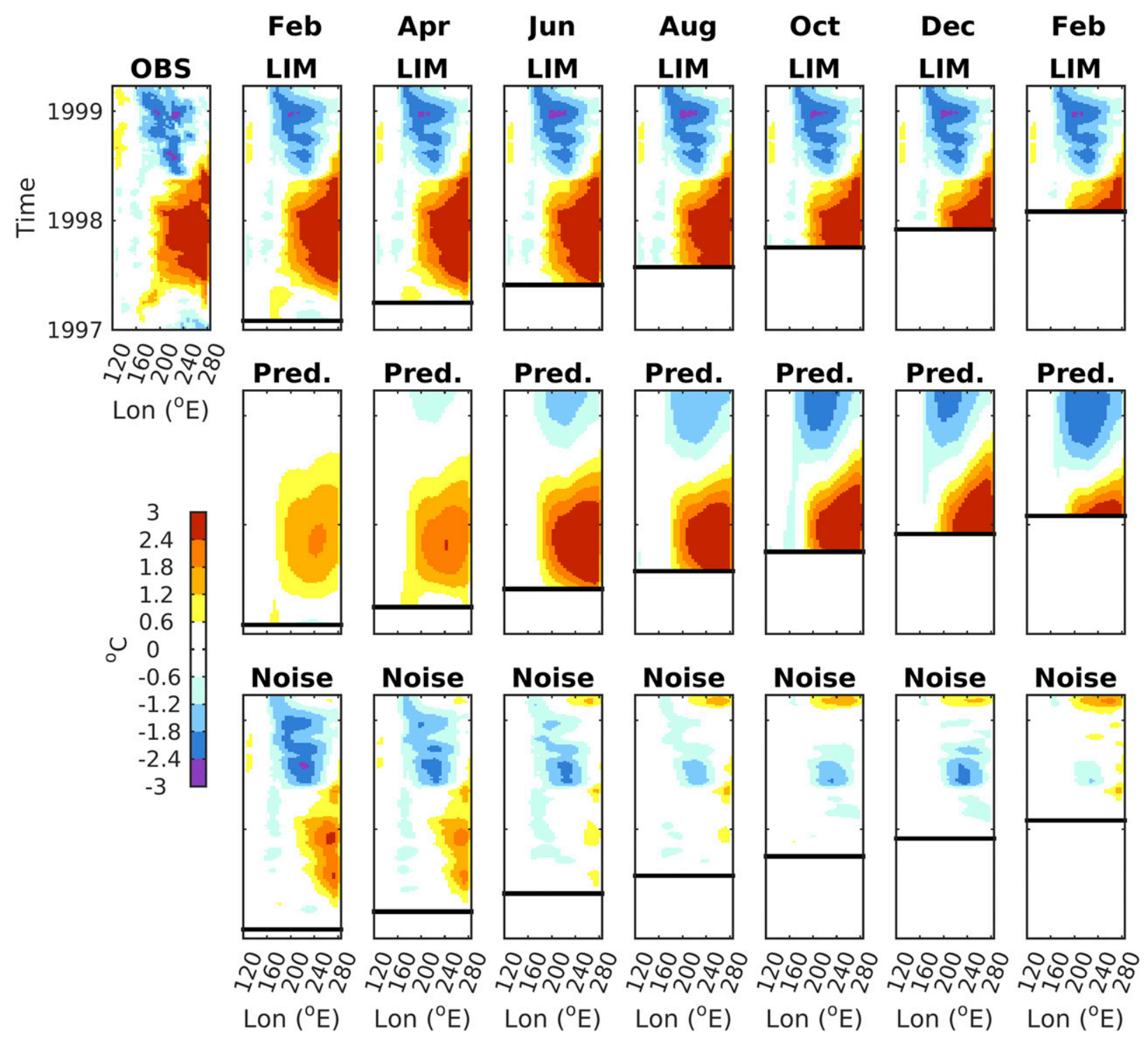

FIG. 8. As in Fig. 5, but for the 1997/98 EP El Niño event.

the EP noise during boreal spring is important for generating a state where deterministic dynamics dominate the event development.

Figure 9 shows the monthly mean uncoupled SLP, 850-mb wind, and OAFLUX noise patterns associated with the development of the 1997/98 event, focusing on March-June 1997 in accord with the RMSE results above. The noise forcing shows strong westerly wind anomalies located along the equator in the central $\mathrm{Pa}$ cific, during March and April of 1997, which match the boreal spring (MAM) EP noise forcing structures in Fig. 3. These results indicate that EP noise forcing, particularly the positive zonal wind anomalies located in the equatorial Pacific early in the year, was important for the observed magnitude and strong eastern Pacific characteristics of the 1997/98 ENSO event. In contrast to the 1982/83 EP El Niño, this noise forcing occurred much earlier, and hence the 1997/98 EP El Niño was predictable with a longer lead time.

\section{c. 2009/10 El Niño event}

Figure 10 shows the role of deterministic dynamics versus noise forcing though Hovmöller diagrams for the 2009/10 CP ENSO event, as before. For any lead time the deterministic dynamics do a poor job at reproducing the observed warming while the noise forcing dominates the development of the event. This shows the importance of noise forcing to the development of the 

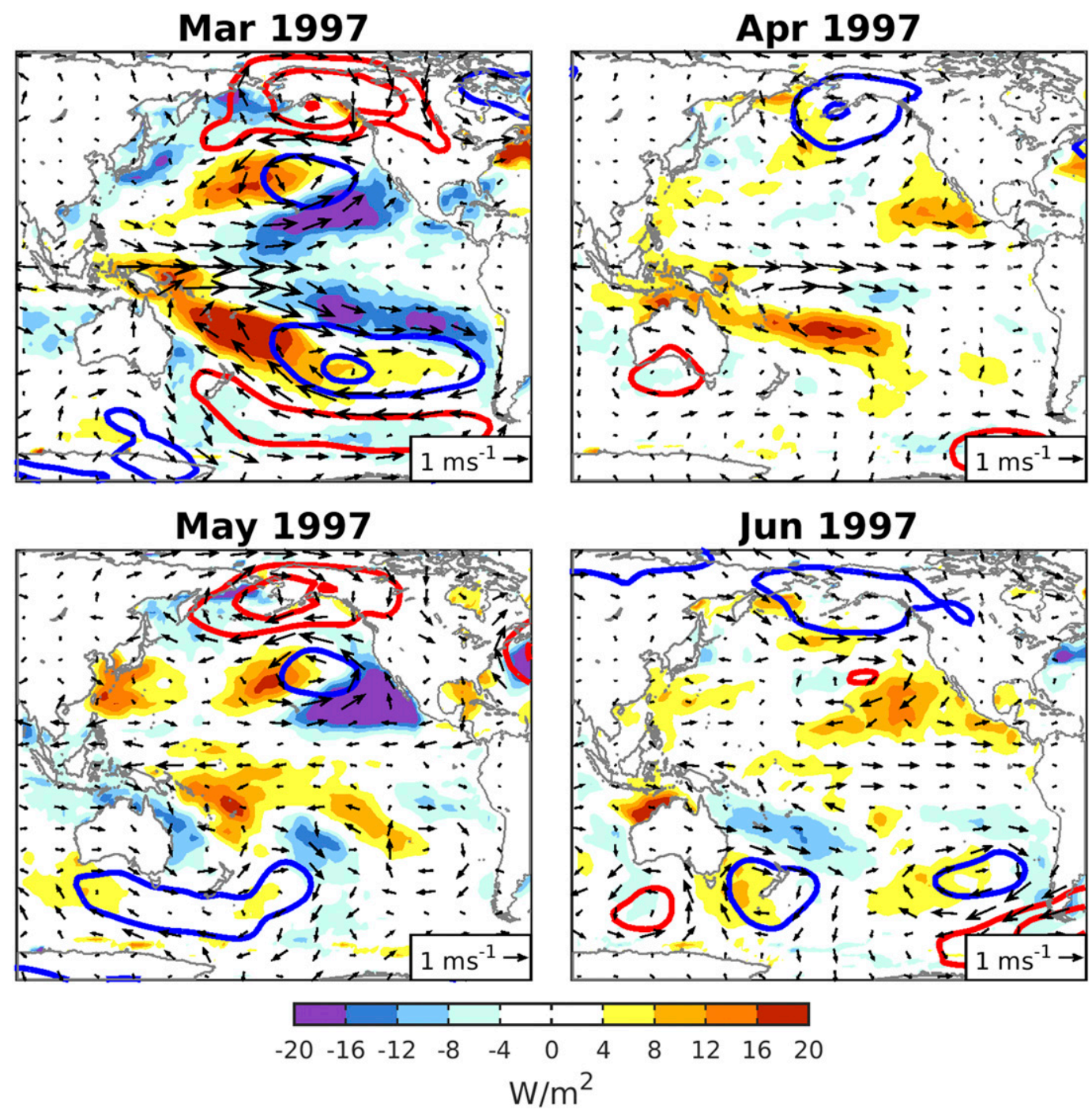

FIG. 9. As in Fig. 7, but for March-June 1997.

2009/10 CP event and its low predictability skill. Additionally, these results show, unlike the deterministic development of the La Niña events that occur after the strong EP events described above, the La Niña event that peaks during the boreal winter of 2010/11 is primarily driven by noise forcing, even after the peak of the 2009/10 El Niño.

To identify the relative importance of EP and CP noise forcing to the 2009/10 CP El Niño and determine during which months the noise forcing is most important, we calculate the CP and EP index RMSEs of the LIM forecasts run without CP and EP noise forcing, respectively (Fig. 6c). The low RMSE values of the EP index (Fig. 6c; black $\times$ s) indicate the LIM run without EP forcing has very little influence on the resulting SST patterns, indicating the $2010 \mathrm{CP}$ event was not highly influenced by EP noise forcing. However, the LIM is unable to accurately reproduce the observed event when the CP noise forcing is removed from the model, especially when the model is initialized prior to June 2009.

The monthly mean structures of the uncoupled SLP, 850-mb wind, and OAFLUX noise that occurs between March and June of 2009 are shown in Fig. 11. The SLP patterns show slight NPO-like SLP anomalies located in the north-central Pacific, which match the $\mathrm{CP}$ noise forcing structures seen in Fig. 3. The dipole SLP structure associated with the NPO is most apparent during April and May; however, the negative SLP anomaly located in the central North Pacific around $40^{\circ} \mathrm{N}$ is evident in all four months. The $850-\mathrm{mb}$ wind structures show extratropical wind anomalies associated with the SLP patterns, as expected. March and April also show strong positive zonal 


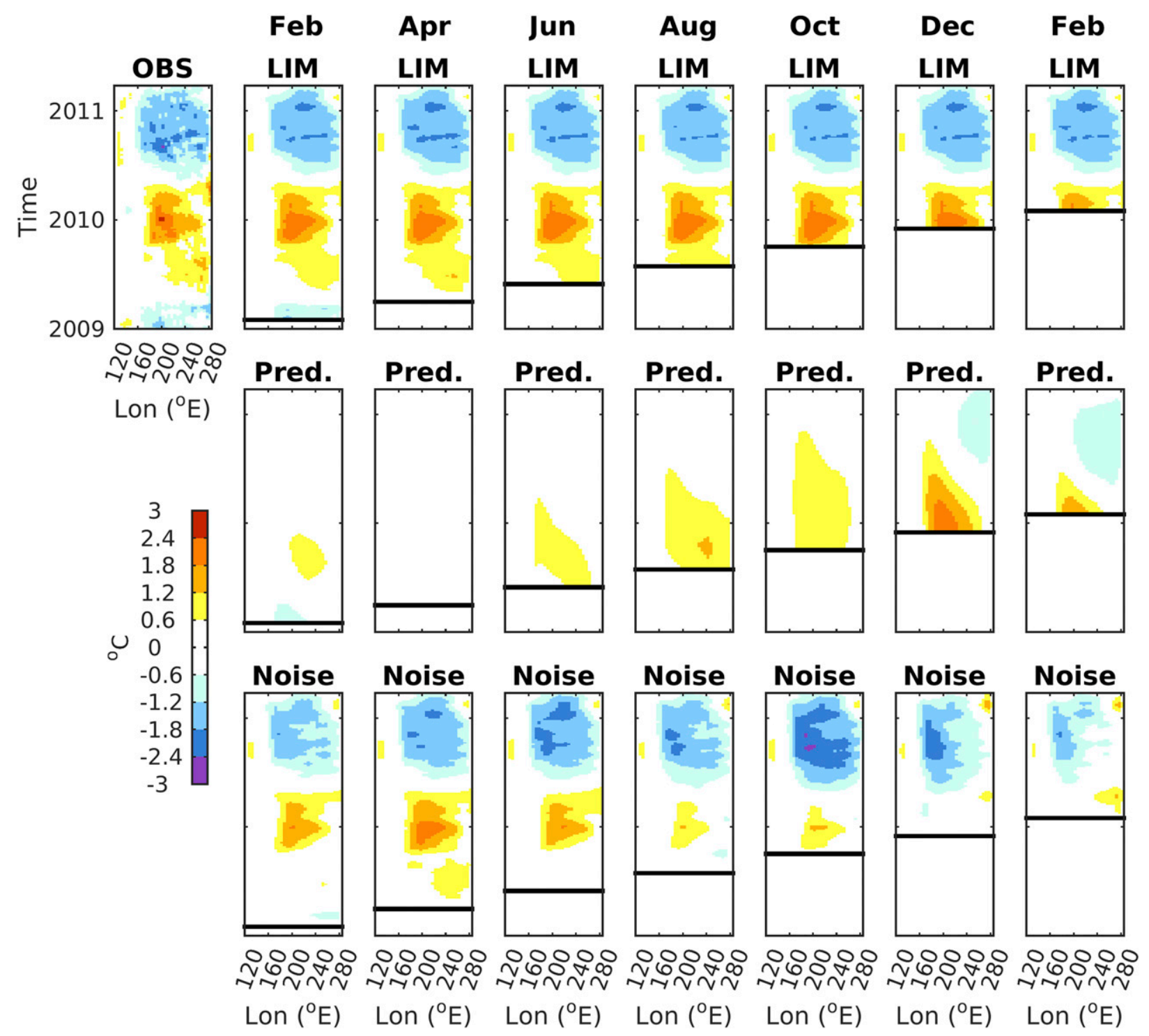

FIG. 10. As in Fig. 5, but for the 2009/10 CP El Niño event.

wind anomalies located along the equator in the central Pacific. These zonal wind patterns closely match the $\mathrm{CP}$ noise forcing structures shown in Fig. 3. Finally, the OAFLUX patterns include downward heat flux anomalies in the subtropics, which project strongly onto the PMM spatial structure. These OAFLUX patterns also agree with the CP noise forcing structures in Fig. 3.

\section{d. 2015/16 El Niño event}

Figure 12 shows the same analysis applied to the strong 2015/16 El Niño. Results show that deterministic dynamics simulated the evolution of the 2015/16 event well with very long lead times. More specifically, these results show that the deterministic dynamics predict a large El Niño event in early boreal spring, and capture the full amplitude of the ensuing event in late boreal summer (August). The noise forcing appears to be especially important during February 2015, and again in July and August 2015, in generating the large-magnitude ENSO event that was observed.

Figure 6d shows the RMSE results to quantify the importance of $\mathrm{CP}$ noise forcing versus EP noise forcing to the 2015/16 CP event. These results show small RMSEs for both the CP and EP indices, except during February and March of 2015, which contain relatively large EP errors. The monthly composite SLP, $850-\mathrm{mb}$ wind, and OAFLUX noise forcing structures for February-May 2015 are shown in Fig. 13. The most striking noise forcing features are the large zonal wind anomalies that occur in the western and central equatorial Pacific during 

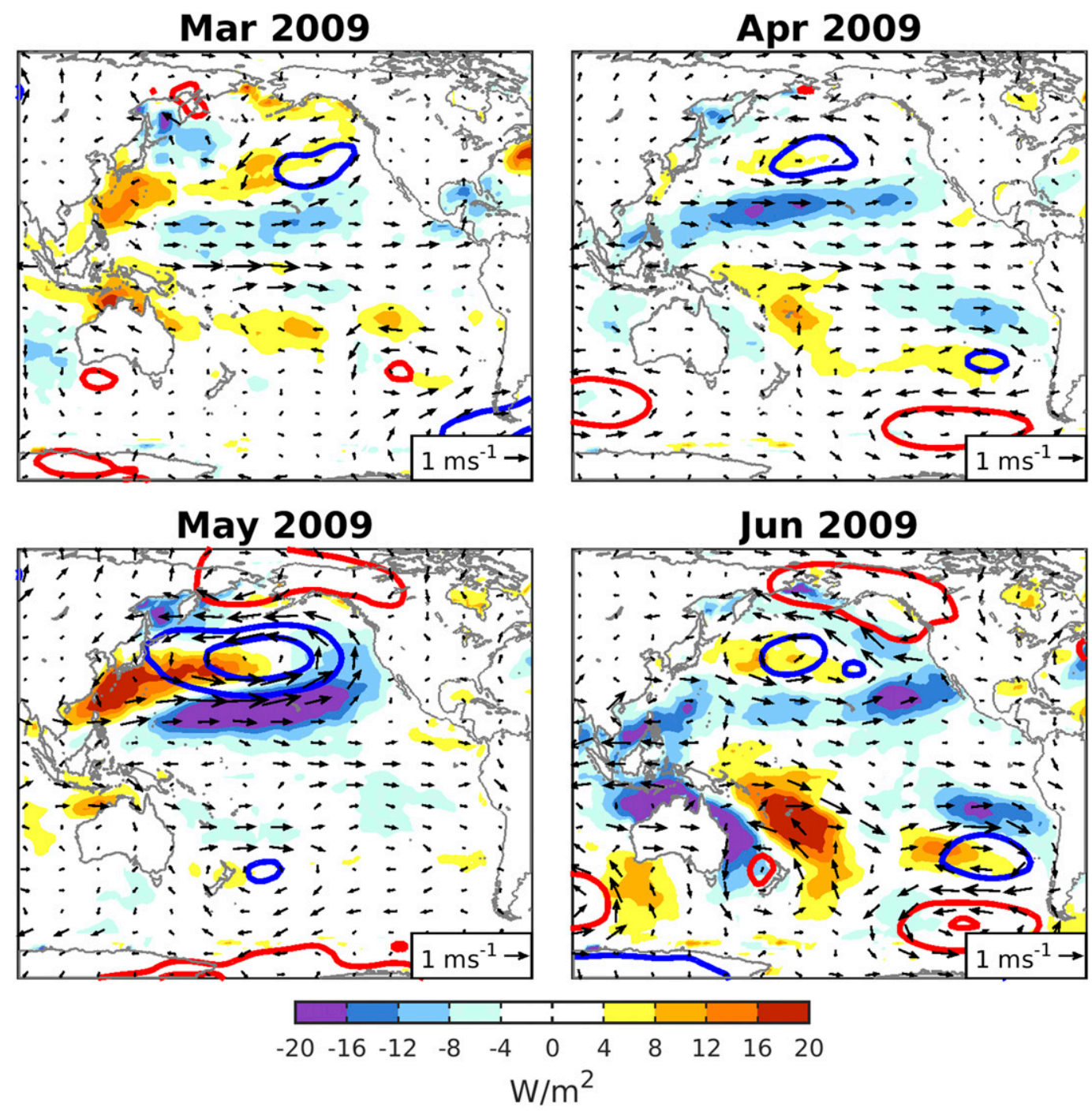

FIG. 11. As in Fig. 7, but for March-June 2009.

February and March. These zonal wind anomalies strongly resemble the MAM EP noise forcing patterns identified in Fig. 3 (right column). The Southern Hemisphere SLP, zonal wind, and OAFLUX anomalies in March all strongly resemble the South Pacific Oscillation of You and Furtado (2017), which is also evident in Figs. 3 and 4 (right columns). The monthly composites (Fig. 13) also show noise patterns that project onto the previously identified CP noise forcing patterns in Figs. 3 and 4. For example, the OAFLUX during February contains a flux into the ocean that resembles the PMM pattern seen in Fig. 4 (left column).

These results show the 2015 ENSO event was largely predictable in nature, due to the dominant role the deterministic dynamics played in the development. Furthermore, this event highlights the diversity of the noise forcing for any given event. The 2015 event is difficult to classify as either a CP event or an EP event as there is a significant projection onto both $\mathrm{CP}$ and $\mathrm{EP}$ patterns (refer to the $\mathrm{CP}$ and EP index time series in Figs. $2 \mathrm{~b}$ and $2 \mathrm{c}$, respectively). This blend of CP and EP characteristics is apparent in the influence of both CP and EP noise forcing structures.

\section{e. 2014 nonevent}

Finally, we analyze 2014 to see if the large-magnitude event that many expected to occur at the end of 2014 was "ruined" by the role of the noise forcing. Most noteworthy, our results suggest no large-magnitude event should have been expected during 2014. The deterministic dynamics, or the predicable component of the LIM, do not forecast an ENSO event occurring at the end of the 2014 calendar year, no matter when the model is 


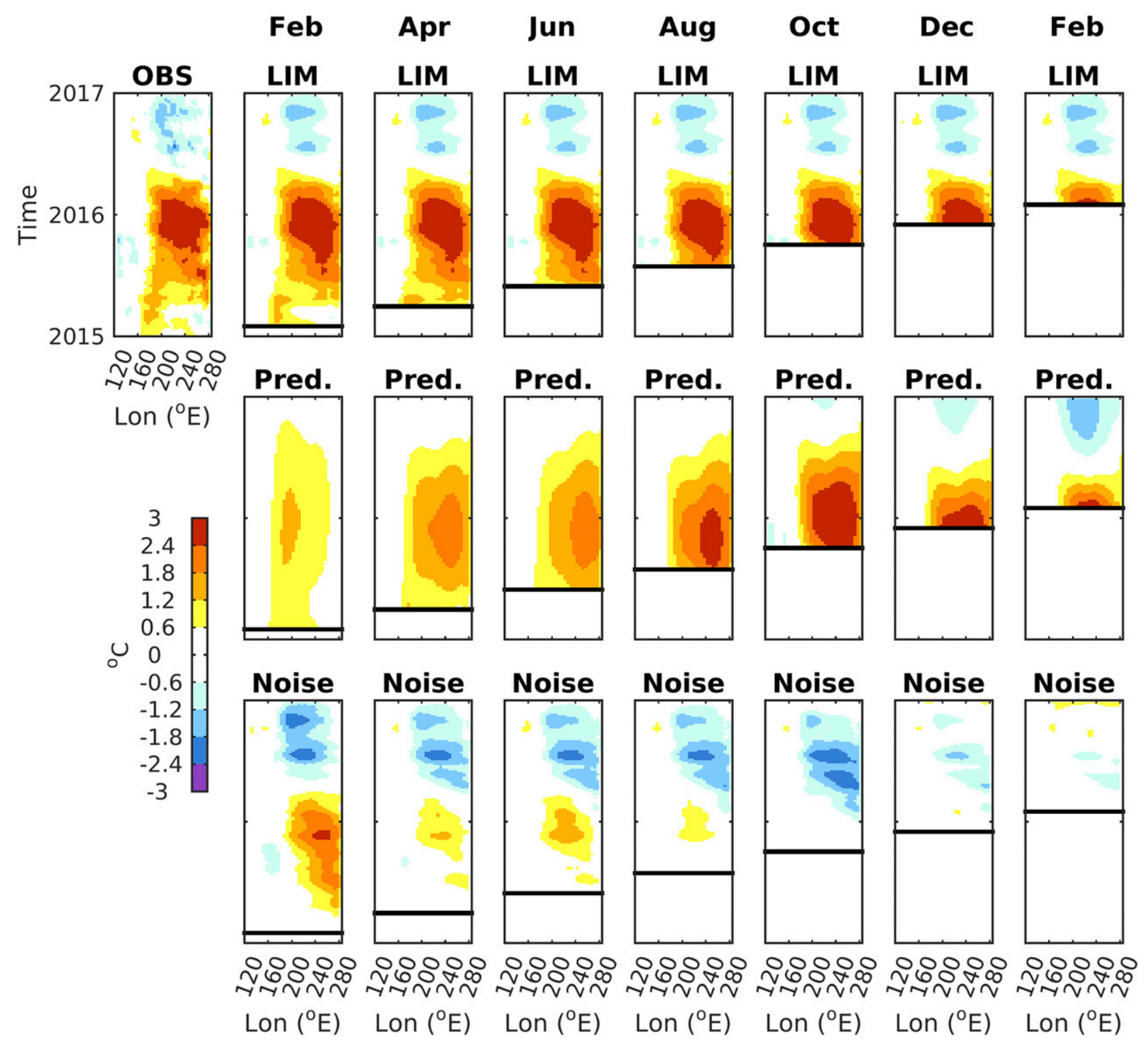

FIG. 12. As in Fig. 5, but for the 2015 El Niño event.

initialized (Fig. 14). This suggests the state of the tropical Pacific during 2014 never contained initial conditions ideal for producing an ENSO event. Recall that forecasts in Fig. 14 are initialized 12 months before those in Fig. 12, so results are not directly comparable. Although the monthly noise composites (Fig. 15) do show easterly wind burst activity during June and July of 2014, which stalled the development of a 2014 El Niño event according to $\mathrm{Hu}$ and Fedorov (2016, 2018), the lack of an ENSO event generated by the deterministic forecast using June initial conditions suggests the WWB noise forcing in February and March was insufficient to generate a state that could develop into an event at the end of the year. Furthermore, our results support the conclusions of Chiodi and
Harrison (2017) that also suggest insufficient WWB activity to produce an ENSO event.

\section{Conclusions and discussion}

This study investigates the role of initial conditions and noise in producing ENSO events with eastern Pacific (EP) or central Pacific (CP) characteristics. A forecast perspective is applied using linear inverse modeling to separate the deterministic evolution of the tropical ocean-atmosphere system from the noiseforced nondeterministic evolution. Within this forecast framework, the noise plays two roles: it can enhance deterministic growth by generating initial conditions 
Feb 2015

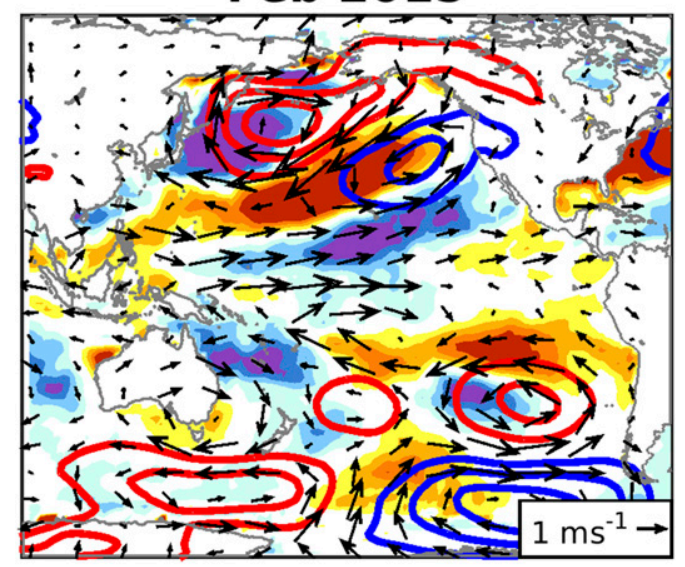

Apr 2015

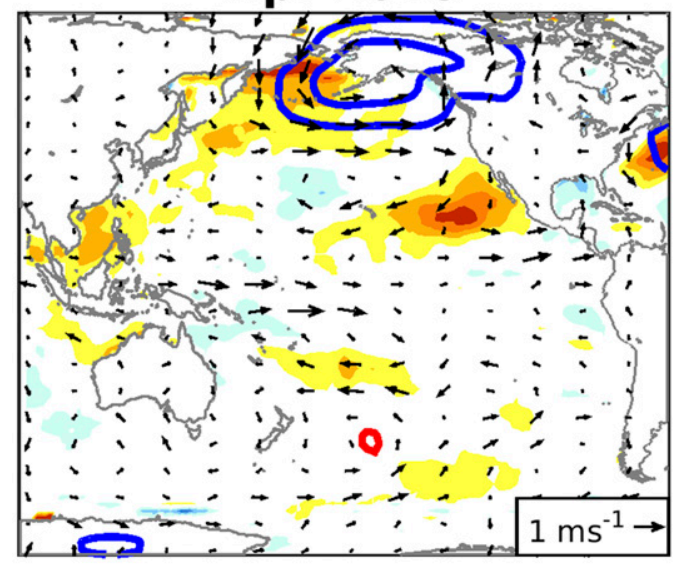

Mar 2015

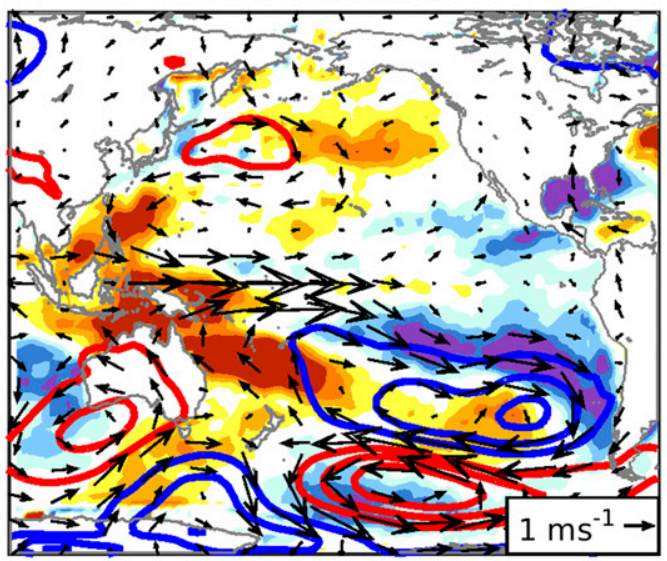

May 2015
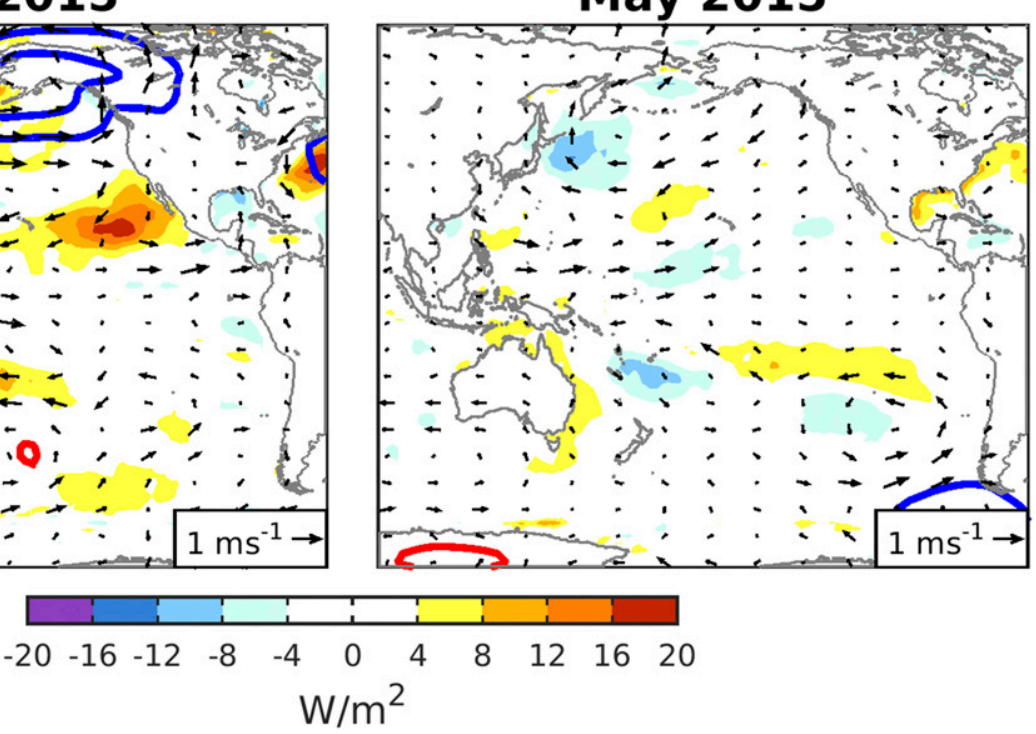

FIG. 13. As in Fig. 7, but for February-May 2015.

with large projection onto optimal initial states or it can lead to nondeterministic growth (forecast error) by pushing the system away from the deterministic trajectory. While many studies have used LIM to identify optimal initial conditions for EP and CP events, the noise forcing capable of exciting those optimal structures has not been previously identified. This study uses a LIM framework to identify specific noise structures capable of exciting $\mathrm{CP}$ and EP optimal initial conditions and then analyzes the role of noise forcing during the 1982/83 and 1997/98 EP ENSO events, the 2009/10 CP ENSO event, the 2015/16 event, and the conditions during 2014.

We first use LIM to calculate the linear dynamics of the tropical Pacific and identify the optimal initial conditions that maximize growth toward EP and CP events.
We then apply a centered-differencing method (Penland and Hartten 2014) to calculate the noise forcing of the tropical Pacific. By projecting the noise forcing onto the $\mathrm{CP}$ and EP optimal initial conditions, we obtain time series of how the noise pushes the system toward $\mathrm{CP}$ or EP optimal initial conditions. These time series are then used to investigate other fields to better understand the structures within the noise forcing related to generating CP and EP growth. Prior studies show the importance of extratropical atmospheric forcing and the seasonal footprinting mechanism in the development of CP ENSO events ( $\mathrm{Yu}$ and Kim 2011); the PMM structure of the CP optimal initial conditions found in this study as well as the corresponding NPO structure of the boreal winter stochastic forcing provide direct empirical evidence in support of these findings. Further, the EP 


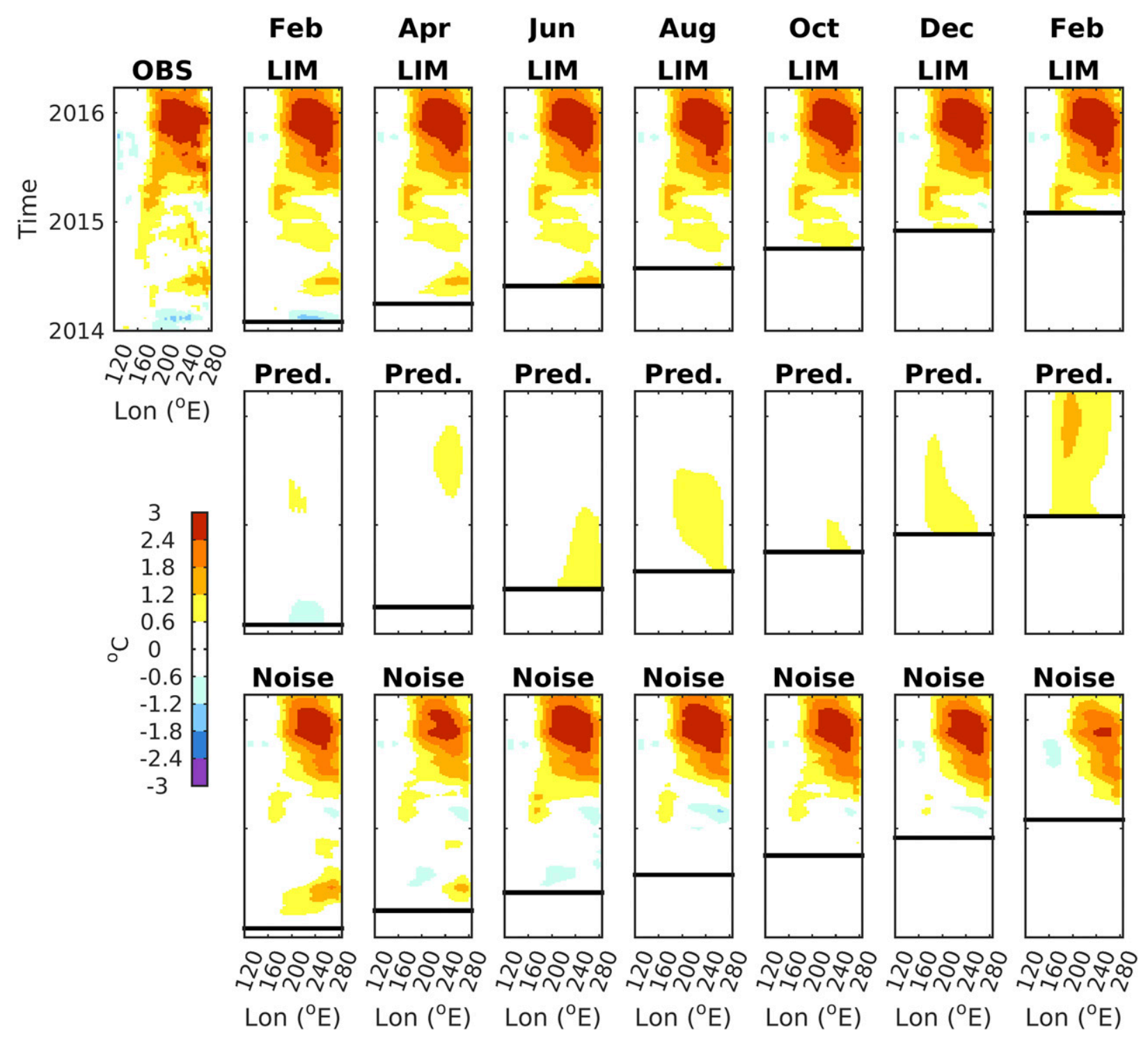

FIG. 14. As in Fig. 5, but for the failed 2014 event.

noise forcing identifies equatorial westerly wind activity near $150^{\circ} \mathrm{E}$ and the South Pacific Oscillation (You and Furtado 2017) as contributors to optimal EP initial conditions.

The LIM framework is then used to investigate the relative roles of initial conditions versus stochastic forcing in the evolution of specific ENSO events. The LIM is integrated forward from specific times along (i) a deterministic trajectory in which the initial conditions are integrated forward with zero noise forcing and (ii) a nondeterministic trajectory in which the initial conditions are set to zero and the LIM is integrated forward using only the estimated noise forcing. The technique accurately captures diversity in the timing and spatial structure of noise forcing although the noise forcing is convolved with the estimated deterministic dynamics.

Diversity in the timing of the initial conditions and noise forcing is especially evident when comparing the 1982/83 and 1997/98 EP El Niño events. Results show that positive zonal wind anomalies play a significant role during the development of both the 1982/83 and 1997/98 EP ENSO events, although the two events evolve under very different conditions. Similar to the conclusions of Takahashi and DeWitte (2016), the large amplitude of the 1982/83 event was related to the strong equatorial wind anomalies in late boreal summer (August and September). We also show that the state of the tropical Pacific prior to October 1982 was not conducive to 

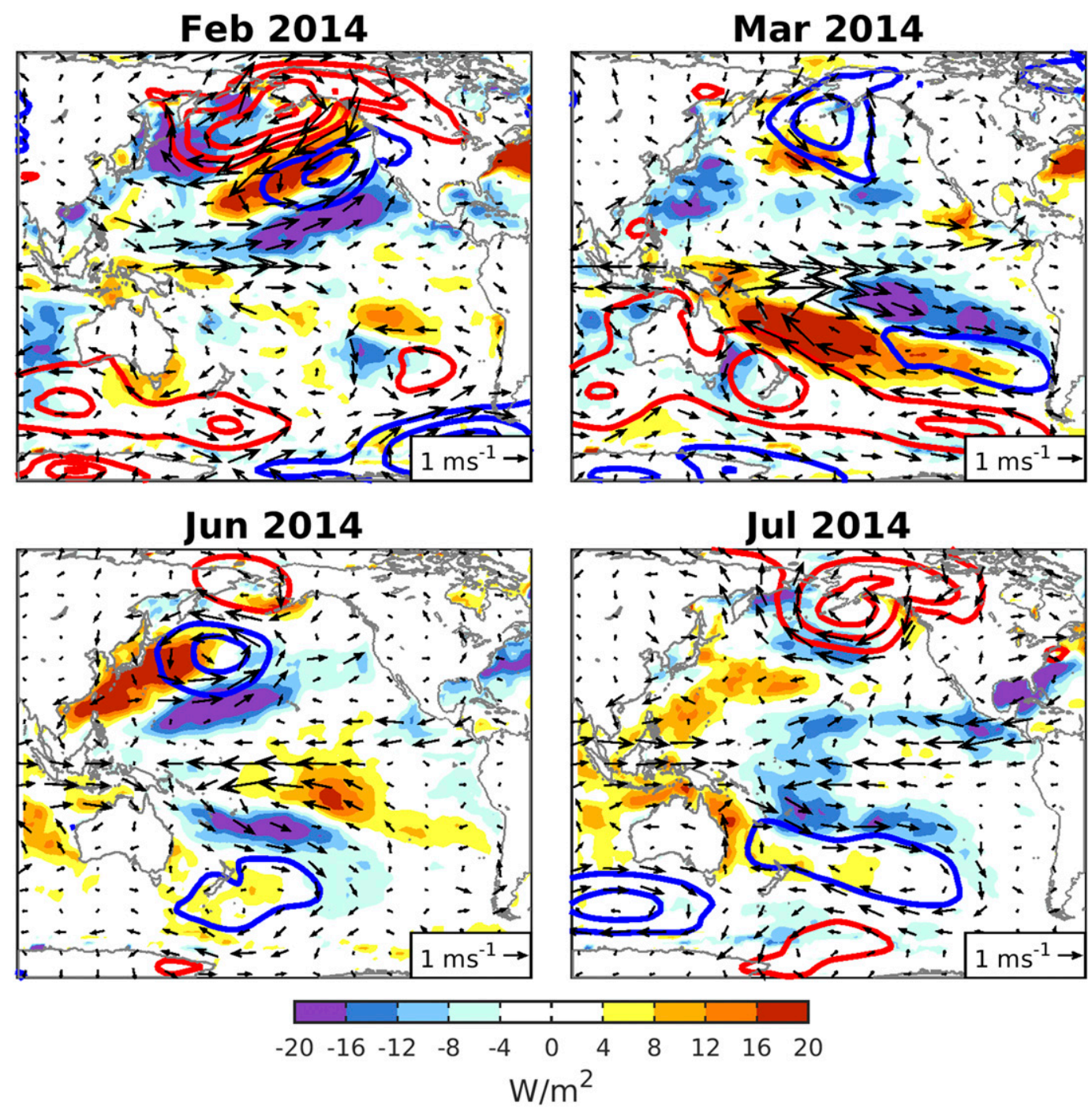

FIG. 15. As in Fig. 7, but for February, March, June, and July 2014. Only the months with large-magnitude noise forcing structures are shown.

producing a large event via the deterministic trajectory. It is possible the limited observations may play a role in the low predictability of the 1982/83 event.

In contrast, the deterministic trajectory for the 1997/ 98 El Niño was predictable using observed initial conditions as early as late winter 1997 (February). Large equatorial westerly wind anomalies in March and April 1997 established a tropical Pacific state that was sufficient for producing a large-amplitude El Niño event by late 1997. Hong et al. (2014) find extreme-magnitude El Niño events (i.e., 1982/83 and 1997/98) are preceded by enhanced low-level westerly wind anomalies in the westcentral Pacific. Furthermore, Harrison (1984) shows a southerly jet prior to the occurrence of the sustained westerly wind anomalies in 1982 may also play a role in the development of the large-magnitude event observed.
Beyond May 1997, noise forcing played very small role in the evolution of the 1997/98 El Niño event. Furthermore, the La Niña conditions following the two extreme El Niño events of 1982/83 and 1997/98 are shown to largely result from the dynamical evolution of the system from their preceding El Niño events.

Analysis of the 2009/10 CP ENSO event highlights the role of the stochastic forcing in producing some ENSO events. The 2009/10 event was largely noise driven throughout the entirety of the event. Only during the late boreal fall of 2009 did the deterministic trajectory capture the amplitude of the event. CP noise forcing during April and May 2009 was especially important for the development of CP characteristics for the resulting event. Further, unlike the 1983/84 and 1998/99 La Niña conditions, the 2010/11 La Niña event 
was largely unpredictable while the 2009/10 El Niño event itself was still developing. However, these results show that the 2010 La Niña event contained some deterministic predictability once the El Niño event reached its peak magnitude, as suggested by Kim et al. (2011).

Not all events evolve along CP or EP trajectories, as evidenced by the 2015/16 event. Strong EP forcing (especially equatorial westerly winds) in February and March 2015 was especially important for setting the stage for the ensuing event. Analysis shows that the highly anticipated 2014 event, which never materialized, was relatively well predicted by the deterministic trajectory throughout 2014.

Our method of estimating noise forcing allows the statistics of the system to determine the assumed dynamics (the LIM), so that we can directly estimate the noise as a residual. An alternative approach for determining noise forcing of ENSO would be to first assume a theoretical model for ENSO variability, and then calculate the additive and multiplicative components of the noise forcing using a predetermined relationship between the system state and the noise, such as by using linear regression to calculate coefficients (Levine and Jin 2017; Levine et al. 2016). Our method includes both the additive component and possibly some contribution from the multiplicative component of the noise [see Martínez-Villalobos et al. (2018) and Sardeshmukh and Sura (2009) for further description of the multiplicative noise contribution to the dynamical operator and noise amplitude], but it does not distinguish between these components. We note that Levine et al. (2016) find modest contributions of the multiplicative noise component only during extreme ENSO events, which should be taken into consideration in interpreting the results in section 4 .

The technique used in this study has some other limitations. For example, the linear approximation in LIM assumes that the system's nonlinear dynamics have much shorter memory (are more rapidly decorrelating) than the linear dynamics. Where and when this assumption is not valid, the LIM will not capture all the nonlinear dynamics properly. [Of course, many CMIP5 models also may not correctly represent nonlinear dynamics, as shown for example in Karamperidou et al. (2017).] LIM is known to have reduced skill in the far eastern Pacific (Newman and Sardeshmukh 2017), which could well be due to unresolved nonlinearity, as well as to strong seasonality that is not included in the linear operator. The relatively short record used to train LIM could allow some deterministic and noise effects to be convolved, especially given the reliance on a truncated EOF space to limit the dimensionality of the predictable dynamics. Still, tests on the validity of LIM in the tropical Pacific herein and in previous studies show LIM performs well in the tropical Pacific (e.g., Penland and Sardeshmukh 1995). Also, Newman and Sardeshmukh (2017) suggested that, since both LIM and multimodel ensemble mean forecasts generally outperform individual CGCMs in the equatorial Pacific, essentially unpredictable nonlinear interactions cause random forecast errors that are averaged out better in multimodel ensemble mean forecasts than in the individual-model ensemble mean forecasts, in agreement with the assumption underlying LIM. Moreover, Chen et al. (2016) show a nonlinear inverse model (NLIM) does not improve tropical Pacific SST forecast results over the regular LIM, and Ding et al. (2018) suggest that most of the central tropical Pacific skill within some NMME models is effectively linear. Further research is being done to test our findings in a coupled general circulation model using both the methodology herein, as well as directly applying the noise forcing structures as an external forcing to a coupled general circulation model.

While the present study highlights some interesting cases, it is important to note the development of any given ENSO event can be influenced by a rich variety of initial conditions and noise structures. Further, these noise structures themselves are a blend of a variety of phenomena that can excite growth in the tropical Pacific. While the role of noise forcing for ENSO development varies greatly for each event and characterizing the structures within the noise forcing is challenging, the present study provides a single framework for parsing through the myriad processes that contribute to ENSO diversity.

Acknowledgments. We wish to thank the reviewers for providing helpful comments. This work was supported by NSF Climate and Large Scale Dynamics Project 1463970.

\section{REFERENCES}

Alexander, M. A., I. Bladé, M. Newman, J. R. Lanzante, N.-C. Lau, and J. D. Scott, 2002: The atmospheric bridge: The influence of ENSO teleconnections on air-sea interaction over the global oceans. J. Climate, 15, 2205-2231, https://doi.org/ 10.1175/1520-0442(2002)015<2205:TABTIO >2.0.CO;2.

_ L. Matrosova, C. Penland, J. D. Scott, and P. Chang, 2008: Forecasting Pacific SSTs: Linear inverse model predictions of the PDO. J. Climate, 21, 385-402, https://doi.org/10.1175/ 2007JCLI1849.1.

An, S.-I., and F. Jin, 2000: An eigen analysis of the interdecadal changes in the structure and frequency of ENSO mode. Geophys. Res. Lett., 27, 2573, https://doi.org/10.1029/1999GL011090.

, and B. Wang, 2000: Interdecadal change of the structure of the ENSO mode and its impact on the ENSO 
frequency. J. Climate, 13, 2044-2055, https://doi.org/10.1175/ 1520-0442(2000)013<2044:ICOTSO > 2.0.CO;2.

Ashok, K., S. K. Behera, S. A. Rao, H. Weng, and T. Yamagata, 2007: El Niño Modoki and its possible teleconnection. J. Geophys. Res., 112, C11007, https://doi.org/10.1029/2006JC003798.

Battisti, D. S., 1988: Dynamics and thermodynamics of a warming event in a coupled tropical atmosphere-ocean model. J. Atmos. Sci., 45, 2889-2919, https://doi.org/10.1175/ 1520-0469(1988)045<2889:DATOAW>2.0.CO;2.

_ , and A. C. Hirst, 1989: Interannual variability in a tropical atmosphere-ocean model: Influence of the basic state, ocean geometry and nonlinearity. J. Atmos. Sci., 46, 1687-1712, https:// doi.org/10.1175/1520-0469(1989)046<1687:IVIATA > 2.0.CO;2.

Behringer, D., and Y. Xue, 2004: Evaluation of the Global Ocean Data Assimilation System at NCEP: The Pacific Ocean. Eighth Symp. on Integrated Observing and Assimilation Systems for Atmosphere, Oceans, and Land Surface, Seattle, WA, Amer. Meteor. Soc., 2.3, https://ams.confex.com/ams/ 84Annual/techprogram/paper_70720.htm.

Boulanger, P., and C. Menkes, 1999: Long equatorial wave reflection in the Pacific Ocean from TOPEX/POSEIDON data during the 1992-1998 period. Climate Dyn., 15, 205-225, https://doi.org/10.1007/s003820050277.

Capotondi, A., 2013: ENSO diversity in the NCAR CCSM4 climate model. J. Geophys. Res. Oceans, 118, 4755-4770, https:// doi.org/10.1002/jgrc.20335.

— ent types of ENSO events. Geophys. Res. Lett., 42, 9952-9960, https://doi.org/10.1002/2015GL066171.

— Lett., 44, 8548-8556, https://doi.org/10.1002/2017GL074515.

— Amer. Meteor. Soc., 96, 921-938, https://doi.org/10.1175/ BAMS-D-13-00117.1.

Carton, J. A., and B. S. Giese, 2008: A reanalysis of ocean climate using Simple Ocean Data Assimilation (SODA). Mon. Wea. Rev., 136, 2999-3017, https://doi.org/10.1175/2007MWR1978.1.

Chang, P., R. Saravanan, T. DelSole, and F. Wang, 2004: Predictability of linear coupled systems. Part I: Theoretical analyses. J. Climate, 17, 1474-1486, https://doi.org/10.1175/ 1520-0442(2004)017<1474:POLCSP > 2.0.CO;2.

Chen, C., M. A. Cane, N. Henderson, D. E. Lee, D. Chapman, D. Kondrashov, and M. D. Chekroun, 2016: Diversity, nonlinearity, seasonality, and memory effect in ENSO simulation and prediction using empirical model reduction. J. Climate, 29, 1809-1830, https://doi.org/10.1175/JCLI-D-15-0372.1.

Chen, D., and Coauthors, 2015: Strong influence of westerly wind bursts on El Niño diversity. Nat. Geosci., 8, 339-345, https:// doi.org/10.1038/ngeo2399.

Chiang, J., and D. Vimont, 2004: Analogous Pacific and Atlantic meridional modes of tropical atmosphere-ocean variability. J. Climate, 17, 4143-4158, https://doi.org/10.1175/JCLI4953.1.

Chiodi, A. M., and D. E. Harrison, 2017: Observed El Niño SSTA development and the effects of easterly and westerly wind events in 2014/15. J. Climate, 30, 1505-1519, https://doi.org/ 10.1175/JCLI-D-16-0385.1.

Diaz, H. F., M. P. Hoerling, and J. K. Eischeid, 2001: ENSO variability, teleconnections and climate change. Int. J. Climatol., 21, 1845-1862, https://doi.org/10.1002/joc.631.

Ding, H., M. Newman, M. A. Alexander, and A. T. Wittenberg, 2018: Skillful climate forecasts of the tropical Indo-Pacific Ocean using model analogs. J. Climate, 31, 5437-5459, https:// doi.org/10.1175/JCLI-D-17-0661.1.
Fedorov, A. V., and S. G. Philander, 2000: Is El Niño changing? Science, 288, 1997-2002, https://doi.org/10.1126/science.288.5473.1997.

$\longrightarrow$, and - , 2001: A stability analysis of tropical oceanatmosphere interactions: Bridging measurements and theory for El Niño. J. Climate, 14, 3086-3101, https://doi.org/10.1175/ 1520-0442(2001)014<3086:ASAOTO >2.0.CO;2.

_ S. Hu, M. Lengaigne, and E. Guilyardi, 2015: The impact of westerly wind bursts and ocean initial state on the development, and diversity of El Niño events. Climate Dyn., 44, 13811401, https://doi.org/10.1007/s00382-014-2126-4.

Gebbie, G., I. Eisenman, A. Wittenberg, and E. Tziperman, 2007: Modulation of westerly wind bursts by sea surface temperature: A semistochastic feedback for ENSO. J. Atmos. Sci., 64, 3281-3295, https://doi.org/10.1175/JAS4029.1.

Harrison, D. E., 1984: The appearance of sustained equatorial surface westerlies during the 1982 Pacific warm event source. Science, 224, 1099-1102, https://doi.org/10.1126/science.224.4653.1099. , and A. M. Chiodi, 2009: Pre- and post-1997/98 westerly wind events and equatorial pacific cold tongue warming. J. Climate, 22, 568-581, https://doi.org/10.1175/2008JCLI2270.1.

Hong, L. C., H. Lin, and F. F. Jin, 2014: A Southern Hemisphere booster of super El Niño. Geophys. Res. Lett., 41, 2142-2149, https://doi.org/10.1002/2014GL059370.

Horii, T., I. Ueki, and K. Hanawa, 2012: Breakdown of ENSO predictors in the 2000s: Decadal changes of recharge/ discharge-SST phase relation and atmospheric intraseasonal forcing. Geophys. Res. Lett., 39, L10707, https://doi.org/ 10.1029/2012GL051740.

Hu, S., and A. V. Fedorov, 2016: Exceptionally strong easterly wind burst stalling El Niño of 2014. Proc. Natl. Acad. Sci. USA, 113, 2005-2010, https://doi.org/10.1073/pnas.1514182113.

_, and _ 2018: The extreme El Niño of 2015-2016: The role of westerly and easterly wind bursts, and preconditioning by the failed 2014 event. Climate Dyn., https://doi.org/10.1007/ s00382-017-3531-2, in press.

Jin, F.-F., 1997: An equatorial ocean recharge paradigm for ENSO. Part I: Conceptual model. J. Atmos. Sci., 54, 830-847, https:// doi.org/10.1175/1520-0469(1997)054<0830:AEORPF>2.0.CO;2.

Kalnay, E., and Coauthors, 1996: The NCEP/NCAR 40-Year Reanalysis Project. Bull. Amer. Meteor. Soc., 77, 437-471, https:// doi.org/10.1175/1520-0477(1996)077<0437:TNYRP>2.0.CO;2.

Kao, H.-Y., and J.-Y. Yu, 2009: Contrasting eastern-Pacific and central-Pacific types of ENSO. J. Climate, 22, 615-632, https:// doi.org/10.1175/2008JCLI2309.1.

Kapur, A., and C. Zhang, 2012: Multiplicative MJO forcing of ENSO. J. Climate, 25, 8132-8147, https://doi.org/10.1175/ JCLI-D-11-00609.1.

Karamperidou, C., F. F. Jin, and J. L. Conroy, 2017: The importance of ENSO nonlinearities in tropical Pacific response to external forcing. Climate Dyn., 49, 2695-2704, https://doi.org/ 10.1007/s00382-016-3475-y.

Karnauskas, K. B., 2013: Can we distinguish canonical El Niño from Modoki? Geophys. Res. Lett., 40, 5246-5251, https:// doi.org/10.1002/grl.51007.

Kim, J.-S., K.-Y. Kim, and S.-W. Yeh, 2012a: Statistical evidence for the natural variation of the central Pacific El Niño. J. Geophys. Res., 117, C06014, https://doi/org/10.1029/2012JC008003.

Kim, S. T., J.-Y. Yu, A. Kumar, and H. Wang, 2012b: Examination of the two types of ENSO in the NCEP CFS model and its extratropical associations. Mon. Wea. Rev., 140, 1908-1923, https://doi.org/10.1175/MWR-D-11-00300.1.

Kim, W., S. W. Yeh, J. H. Kim, J. S. Kug, and M. Kwon, 2011: The unique 2009-2010 El Niño event: A fast phase transition of 
warm pool El Niño to la Niña. Geophys. Res. Lett., 38, L15809, https://doi.org/10.1029/2011GL048521.

Kirtman, B. P., and Coauthors, 2014: The North American Multimodel Ensemble: Phase-1 seasonal-to-interannual prediction; phase-2 toward developing intraseasonal prediction. Bull. Amer. Meteor. Soc., 95, 585-601, https://doi.org/ 10.1175/BAMS-D-12-00050.1.

Kug, J. S., F. F. Jin, and S.-I. An, 2009: Two types of El Niño events: Cold tongue El Niño and warm pool El Niño. J. Climate, 22, 1499-1515, https://doi.org/10.1175/2008JCLI2624.1.

_ J. Choi, S.-I. An, F. F. Jin, and A. T. Wittenberg, 2010a: Warm pool and cold tongue El Niño events as simulated by the GFDL 2.1 coupled GCM. J. Climate, 23, 1226-1239, https:// doi.org/10.1175/2009JCLI3293.1.

_, K. P. Sooraj, T. Li, and F. F. Jin, 2010b: Precursors of the El Niño/La Niña onset and their interrelationship. J. Geophys. Res., 115, D05106, https://doi.org/10.1029/2009JD0128611.

Levine, A. F. Z., and F.-F. Jin, 2010: Noise-induced instability in the ENSO recharge oscillator. J. Atmos. Sci., 67, 529-542, https://doi.org/10.1175/2009JAS3213.1.

— , and - 2017: A simple approach to quantifying the noiseENSO interaction. Part I: Deducing the state-dependency of the windstress forcing using monthly mean data. Climate Dyn., 48, 1-18, https://doi.org/10.1007/s00382-015-2748-1.

,$- \ldots$, and M. J. McPhaden, 2016: Extreme noise-extreme El Niño: How state-dependent noise forcing creates El Niño-La Niña asymmetry. J. Climate, 29, 5483-5499, https://doi.org/ 10.1175/JCLI-D-16-0091.1.

Lopez, H., B. P. Kirtman, E. Tziperman, and G. Gebbie, 2013: Impact of interactive westerly wind bursts on CCSM3. Dyn. Atmos. Oceans, 59, 24-51, https://doi.org/10.1016/j.dynatmoce.2012.11.001.

Martínez-Villalobos, C., D. J. Vimont, C. Penland, M. Newman, and J. D. Neelin, 2018: Calculating state-dependent noise in a linear inverse model framework. J. Atmos. Sci., 75, 479-496, https://doi.org/10.1175/JAS-D-17-0235.1.

Martín-Rey, M., I. Polo, B. Rodríguez-Forseca, and F. Kucharski, 2012: Changes in the interannual variability of the tropical Pacific as a response to an equatorial Atlantic forcing. Sci. Mar., 76 (S1), 105-116, https://doi.org/10.3989/scimar.03610.19A.

McPhaden, M. J., 1999: Genesis and evolution of the 1997-98 El Niño. Science, 283, 950-955, https://doi.org/10.1126/ science.283.5404.950.

Meinen, C. S., and M. J. McPhaden, 2000: Observations of warm water volume changes in the equatorial Pacific and their relationship to El Niño and La Niña. J. Climate, $\mathbf{1 3}$, 3551-3559, https://doi.org/10.1175/1520-0442(2000)013<3551: OOWWVC $>2.0 . \mathrm{CO} ; 2$.

Neelin, J. D., D. S. Battisti, A. C. Hirst, F.-F. Jin, Y. Wakata, T. Yamagata, and S. E. Zebiak, 1998: ENSO theory. J. Geophys. Res., 103, 14 261-14 290, https://doi.org/10.1029/97JC03424.

Newman, M., 2007: Interannual to decadal predictability of tropical and North Pacific sea surface temperatures. J. Climate, 20, 2333-2356, https://doi.org/10.1175/JCLI4165.1.

—_, and P. D. Sardeshmukh, 2017: Are we near the predictability limit of tropical Indo-Pacific sea surface temperatures? Geophys. Res. Lett., 44, 8520-8529, https://doi.org/ 10.1002/2017GL074088.

,$- \ldots$, and C. Penland, 2009: How important is air-sea coupling in ENSO and MJO evolution? J. Climate, 22, 2958-2977, https://doi.org/10.1175/2008JCLI2659.1.

_ M. A. Alexander, and J. D. Scott, 2011a: An empirical model of tropical ocean dynamics. Climate Dyn., 37, 1823-1841, https://doi.org/10.1007/s00382-011-1034-0.
- S.-I. Shin, and M. A. Alexander, 2011b: Natural variation in ENSO flavors. Geophys. Res. Lett., 38, L14705, https://doi.org/ 10.1029/2011GL047658.

Park, J.-Y., S.-W. Yeh, J.-S. Kug, and J. Yoon, 2013: Favorable connections between seasonal footprinting mechanism and $\mathrm{El}$ Niño. Climate Dyn., 40, 1169-1181, https://doi.org/10.1007/ s00382-012-1477-y.

Penland, C., 1996: A stochastic model of IndoPacific sea surface temperature anomalies. Physica $D, \mathbf{9 8}, 534-558$, https://doi.org/ 10.1016/0167-2789(96)00124-8.

— , and T. Magorian, 1993: Prediction of Niño 3 sea surface temperatures using linear inverse modeling. J. Climate, 6, 1067-1076, https://doi.org/10.1175/1520-0442(1993)006<1067: PONSST $>2.0$.CO;2.

, and P. Sardeshmukh, 1995: The optimal growth of tropical sea surface temperature anomalies. J. Climate, 8, 1999-2024, https:// doi.org/10.1175/1520-0442(1995)008<1999:TOGOTS > 2.0.CO;2. , and L. Matrosova, 1998: Prediction of tropical Atlantic sea surface temperatures using linear inverse modeling. J. Climate, 11, 483-496, https://doi.org/10.1175/1520-0442(1998)011<0483: POTASS $>2.0 . \mathrm{CO} ; 2$.

, and - 2006: Studies of El Niño and interdecadal variability in tropical sea surface temperatures using a nonnormal filter. J. Climate, 19, 5796-5815, https://doi.org/ 10.1175/JCLI3951.1.

$\longrightarrow$, and - 2008: A Southern Hemisphere footprint in American Midwest precipitation. Geophys. Res. Lett., 35, L09703, https://doi.org/10.1029/2008GL033612.

_ Atlantic sea surface temperatures by the North Atlantic Oscillation. Geophys. Res. Lett., 41, 2126-2132, https://doi.org/ 10.1002/2014GL059252.

Perez, C., A. Moore, J. Zavala-Garay, and R. Kleeman, 2005: A comparison of the influence of additive and multiplicative stochastic forcing on a coupled model of ENSO. J. Climate, 18, 5066-5085, https://doi.org/10.1175/JCLI3596.1.

Rayner, N. A., D. E. Parker, E. B. Horton, C. K. Folland, L. V. Alexander, D. P. Rowell, E. C. Kent, and A. Kaplan 2003: Global analyses of sea surface temperature, sea ice, and night marine air temperature since the late nineteenth century. J. Geophys. Res., 108, 4407, https://doi.org/10.1029/2002JD002670.

Reynolds, R. W., N. A. Rayner, T. M. Smith, D. C. Stokes, and W. Wang, 2002: An improved in situ and satellite SST analysis for climate. J. Climate, 15, 1609-1625, https://doi.org/10.1175/ 1520-0442(2002)015<1609:AIISAS > 2.0.CO;2.

Rodríguez-Fonseca, B., I. Polo, J. García-Serrano, T. Losada, E. Mohino, C. R. Mechoso, and F. Kucharski, 2009: Are Atlantic Niños enhancing Pacific ENSO events in recent decades? Geophys. Res. Lett., 36, L20705, https://doi.org/ 10.1029/2009GL040048.

Roulston, M. S., and J. D. Neelin, 2000: The response of an ENSO model to climate noise, weather noise and intraseasonal forcing. Geophys. Res. Lett., 27, 3723-3726, https://doi.org/ 10.1029/2000GL011941.

Sardeshmukh, P. D., and P. Sura, 2009: Reconciling non-Gaussian climate statistics with linear dynamics. J. Climate, 22, 11931207, https://doi.org/10.1175/2008JCLI2358.1.

Suarez, M. J., and P. S. Schopf, 1988: A delayed action oscillator for ENSO. J. Atmos. Sci., 45, 3283-3287, https://doi.org/10.1175/ 1520-0469(1988)045<3283:ADAOFE > 2.0.CO;2.

Takahashi, K., and B. DeWitte, 2016: Strong and moderate nonlinear El Niño regimes. Climate Dyn., 46, 1627-1645, https:// doi.org/10.1007/s00382-015-2665-3. 
- A. Montecinos, K. Goubanova, and B. Dewitte, 2011: ENSO regimes: Reinterpreting the canonical and Modoki El Niño. Geophys. Res. Lett., 38, L10704, https://doi.org/10.1029/2011GL047364.

Tziperman, E., L. Zanna, and C. Penland, 2008: Nonnormal thermohaline circulation dynamics in a coupled ocean-atmosphere GCM. J. Phys. Oceanogr., 38, 588-604, https://doi.org/10.1175/ 2007JPO3769.1.

Vimont, D. J., D. S. Battisti, and A. C. Hirst, 2001: Footprinting: A seasonal connection between the tropics and mid-latitudes. Geophys. Res. Lett., 28, 3923-3926, https://doi.org/10.1029/ 2001GL013435.

,$- \ldots$, and — 2003a: The seasonal footprinting mechanism in the CSIRO coupled general circulation models. J. Climate, 16, 2653-2667, https://doi.org/10.1175/1520-0442(2003)016<2653: TSFMIT $>2.0 . \mathrm{CO} ; 2$

— printing mechanism in the Pacific: Implications for ENSO. J. Climate, 16, 2668-2675, https://doi.org/10.1175/ 1520-0442(2003)016<2668:TSFMIT>2.0.CO;2.

- M. Alexander, and A. Fontaine, 2009: Midlatitude excitation of tropical variability in the Pacific: The role of thermodynamic coupling and seasonality. J. Climate, 22, 518-534, https://doi.org/10.1175/2008JCLI2220.1.

, — - and M. Newman, 2014: Optimal growth of central and east Pacific ENSO events. Geophys. Res. Lett., 41, 4027-4034, https://doi.org/10.1002/2014GL059997.
Wallace, J. M., E. M. Rasmusson, T. P. Mitchell, V. E. Kousky, E. S. Sarachik, and H. von Storch, 1998: On the structure and evolution of ENSO-related climate variability in the tropical Pacific: Lessons from TOGA. J. Geophys. Res., 103, 1424114 259, https://doi.org/10.1029/97JC02905.

Wang, B., and S. I. An, 2002: A mechanism for decadal changes of ENSO behavior: Roles of background wind changes. Climate Dyn., 18, 475-486, https://doi.org/10.1007/ s00382-001-0189-5.

Yeh, S., J. Kug, B. Dewitte, M. Kwon, B. P. Kirtman, and F. Jin, 2009: El Niño in a changing climate. Nature, 461, 511-514, https://doi.org/10.1038/nature08316.

You, Y., and J. C. Furtado, 2017: The role of South Pacific atmospheric variability in the development of different types of ENSO. Geophys. Res. Lett., 44, 7438-7446, https://doi.org/ 10.1002/2017GL073475.

Yu, J.-Y., and S. T. Kim, 2011: Relationships between extratropical sea level pressure variations and the central Pacific and eastern Pacific types of ENSO. J. Climate, 24, 708-720, https://doi.org/ 10.1175/2010JCLI3688.1.

Zebiak, S. E., and M. A. Cane, 1987: A model El Niño-Southern Oscillation. Mon. Wea. Rev., 115, 2262-2278, https://doi.org/ 10.1175/1520-0493(1987)115<2262:AMENO>2.0.CO;2.

Zhang, L., P. Chang, and L. Ji, 2009: Linking the Pacific meridional mode to ENSO: Coupled model analysis. J. Climate, 22, 34883505, https://doi.org/10.1175/2008JCLI2473.1. 